University of South Florida

DIGITAL COMMONS Digital Commons @ University of @ UNIVERSITY OF SOUTH FLORIDA South Florida

$5-1-2017$

\title{
Mobility Case Studies: Where Integrated Corridor Management Has Worked and Why
}

CUTR

Follow this and additional works at: https://digitalcommons.usf.edu/cutr_nctr

\author{
Recommended Citation \\ "Mobility Case Studies: Where Integrated Corridor Management Has Worked and Why," National Center for \\ Transit Research (NCTR) Report No. CUTR-NCTR-RR-2017-01, Center for Urban Transportation Research, \\ University of South Florida, 2017. \\ DOI: https://doi.org/10.5038/CUTR-NCTR-RR-2017-01 \\ Available at: https://scholarcommons.usf.edu/cutr_nctr/43
}

This Technical Report is brought to you for free and open access by the National Center for Transit Research (NCTR) Archive (2000-2020) at Digital Commons @ University of South Florida. It has been accepted for inclusion in Research Reports by an authorized administrator of Digital Commons @ University of South Florida. For more information, please contact digitalcommons@usf.edu. 


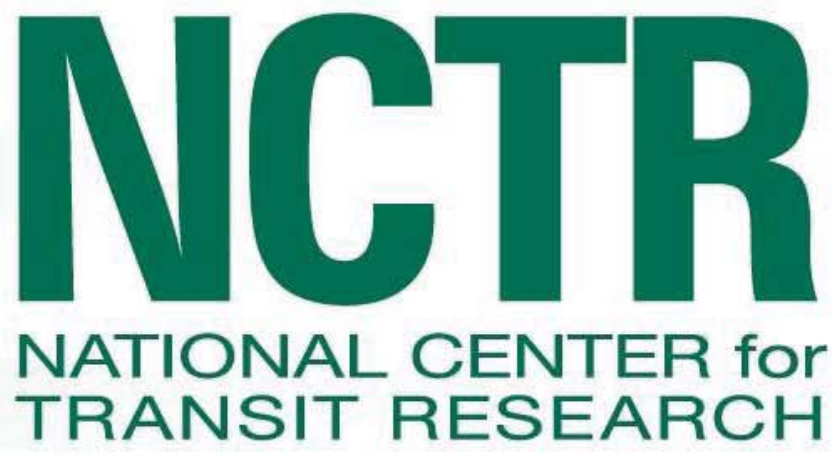

\section{Mobility Case Studies: Where Integrated Corridor Management Has Worked and Why}

Final Report

May 2017

Project No. UIC 2117-9050-02-C

PREPARED FOR 


\section{Mobility Case Studies: Where Integrated Corridor Management Has Worked and Why}

Final Report

Prepared for:

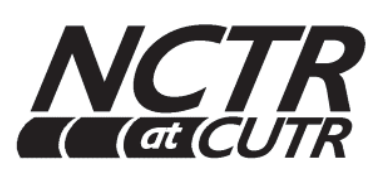

National Center for Transit Research

University of South Florida

Prepared by:

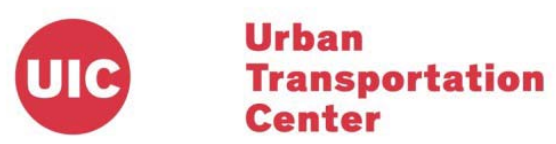

The Urban Transportation Center at the University of Illinois at Chicago 412 South Peoria Street, 340 CUPPAH

Chicago, IL 60607-7036

P. S. Sriraj, PhD

Paul Metaxatos, PhD

Jake Rueter

Adam Barnum

Margarita Bernal

May 2017 


\section{Disclaimer}

The contents of this report reflect the views of the authors, who are responsible for the facts and the accuracy of the information presented herein. This document is disseminated under the sponsorship of the U.S. Department of Transportation's University Transportation Centers Program, in the interest of information exchange. The U.S. Government assumes no liability for the contents or use thereof. 
TECHNICAL REPORT STANDARD TITLE PAGE

\begin{tabular}{|c|c|c|}
\hline 1. Report No. & 2. Government Accession No. & 3. Recipient's Catalog No. \\
\hline \multirow{2}{*}{\multicolumn{2}{|c|}{$\begin{array}{l}\text { 4. Title and Subtitle } \\
\text { Mobility Case Studies: Where Integrated Corridor Management Has Worked } \\
\text { and Why }\end{array}$}} & $\begin{array}{l}\text { 5. Report Date } \\
\text { May } 2017\end{array}$ \\
\hline & & 6. Performing Organization Code \\
\hline \multicolumn{2}{|c|}{$\begin{array}{l}\text { 7. Author(s) } \\
\text { P. S. Sriraj, PhD, Paul Metaxatos, PhD, Jake Rueter, Adam Barnum, } \\
\text { Margarita Bernal }\end{array}$} & 8. Performing Organization Report No. \\
\hline \multirow{3}{*}{\multicolumn{2}{|c|}{$\begin{array}{l}\text { 9. Performing Organization Name and Address } \\
\text { The Urban Transportation Center at the University of Illinois Chicago } \\
412 \text { South Peoria Street, } 340 \text { CUPPAH } \\
\text { Chicago, IL } 60607-7036\end{array}$}} & 10. Work Unit No. (TRAIS) \\
\hline & & \\
\hline & & 11. Contract or Grant No. \\
\hline \multirow{3}{*}{\multicolumn{2}{|c|}{$\begin{array}{l}\text { 12. Sponsoring Agency Name and Address } \\
\text { National Center for Transit Research } \\
\text { Center for Urban Transportation Research } \\
\text { University of South Florida } \\
4202 \text { East Fowler Avenue, CUT100, Tampa, FL 33620-5375 }\end{array}$}} & 13. Type of Report and Period Covered \\
\hline & & \\
\hline & & 14. Sponsoring Agency Code \\
\hline
\end{tabular}

\section{Supplementary Notes}

\section{Abstract}

Mobility management and improvement have become the focal point of the federal, state, and local transportation agencies over the last decade. Even with decreasing vehicle-miles-traveled (VMT) over the same time span, the congestion and delays have not improved leading to a renewed focus on multimodal solutions at all levels. While multimodalism has been part of the transportation vocabulary for a long time, and has been aided by legislation to some extent, it has not been embraced into practice at a large scale. Advances in technology (autonomous vehicles, ridesharing services, transportation network companies, improved dynamic wayfinding systems, as well as improved infrastructure) are providing the paradigm shift needed to look at mobility management in a renewed light. The Greater Chicagoland Northeastern Illinois region is no different from many of the most congested regions in the country, in the sense that the vehicle hours of delay for both passenger and freight are among the highest in the country on an annual basis. This report focuses on this region while drawing on the experiences from other parts of the country to set the stage for detailing the state of multimodal transportation or integrated transportation system in northeastern Illinois.

\begin{tabular}{l|l} 
17. Key Words & 18. Distribution Statement
\end{tabular}

19. Security Classif. (of this report)

Unclassified

Form DOT F 1700.7
20. Security Classif. (of this page) Unclassified
21. No. of Pages

22. Price 


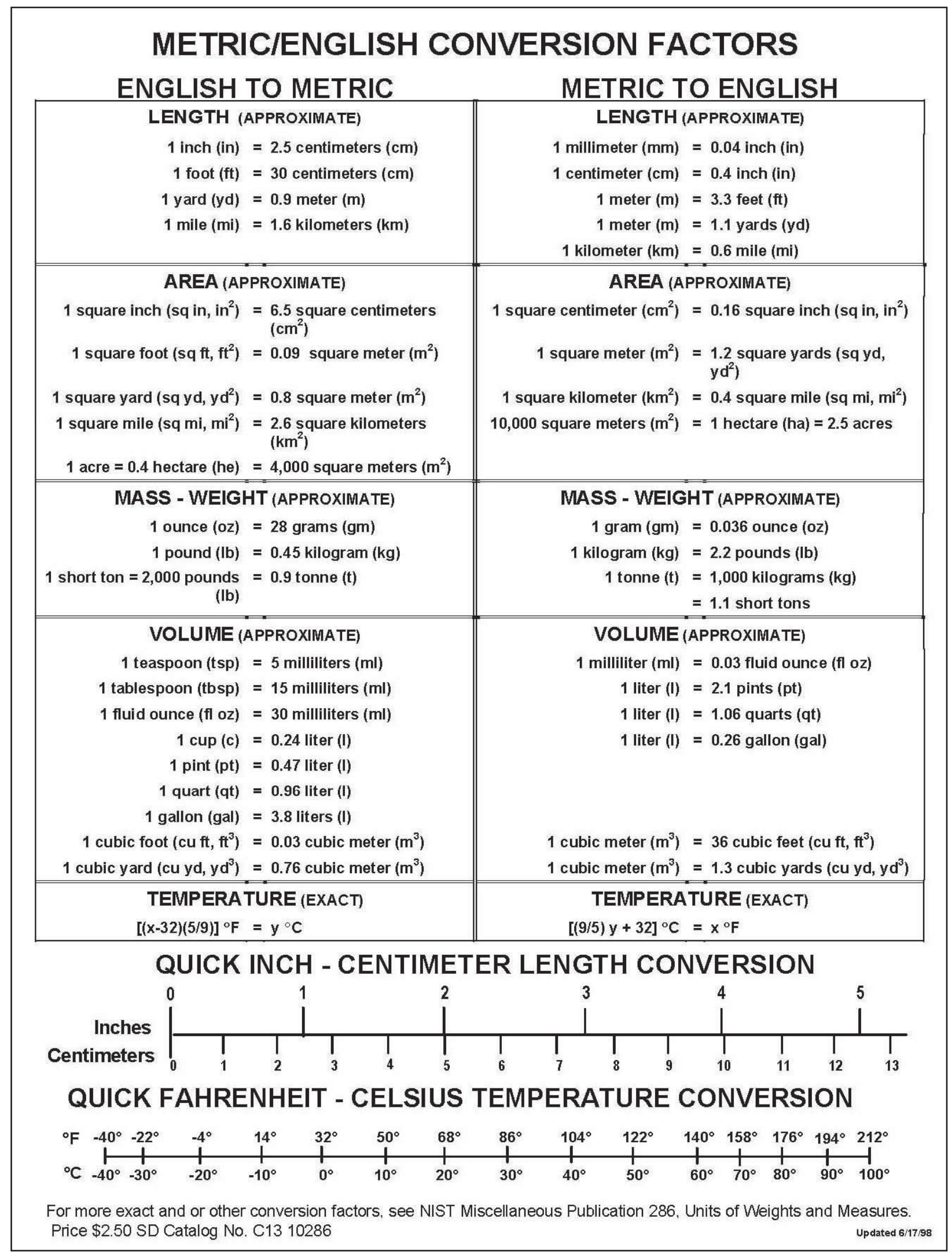




\section{TABLE OF CONTENTS}

INTRODUCTION

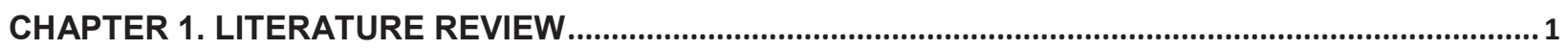

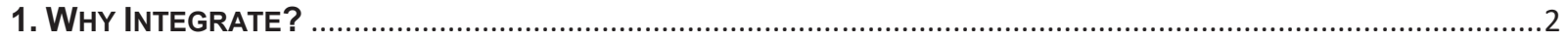

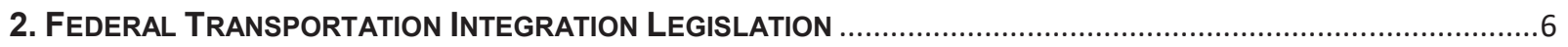

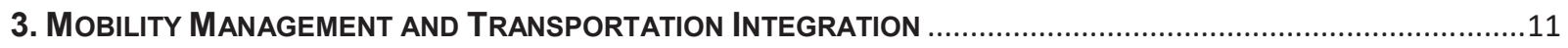

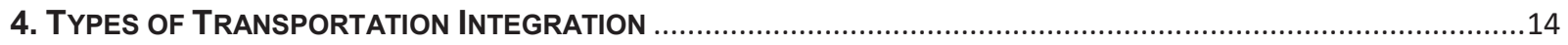

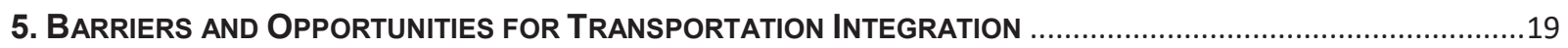

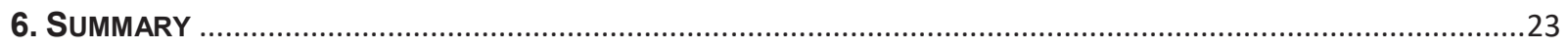

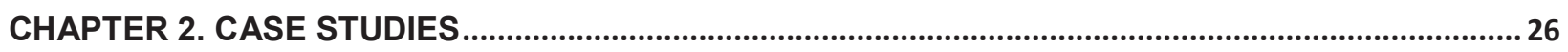

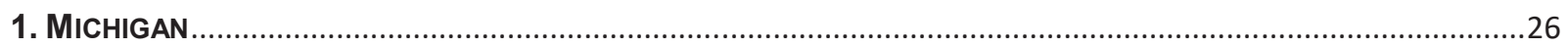

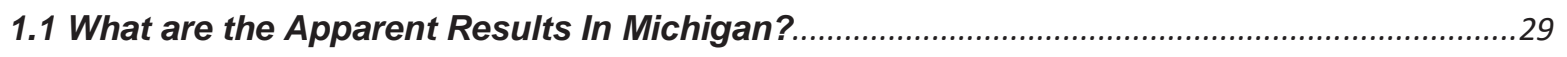

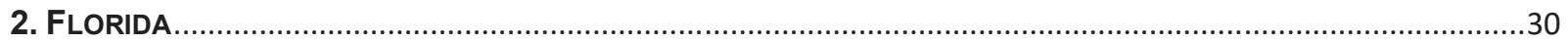

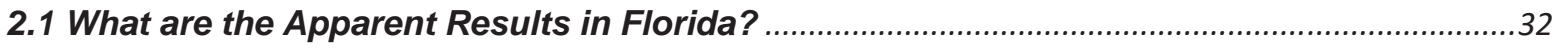

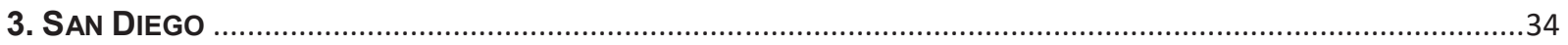

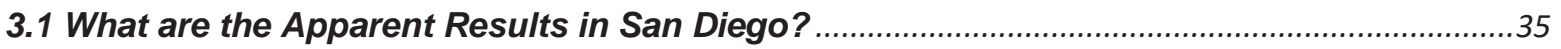

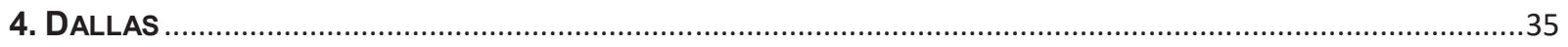

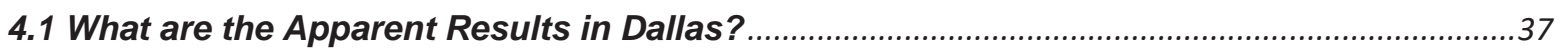

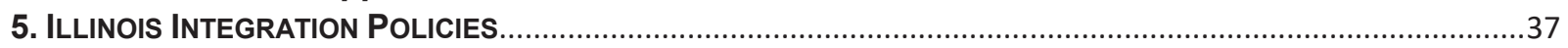

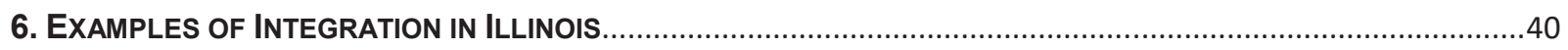

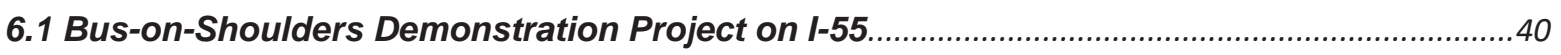

6.2 Parking Management Guidance System - A Chicago Case ..................................................4

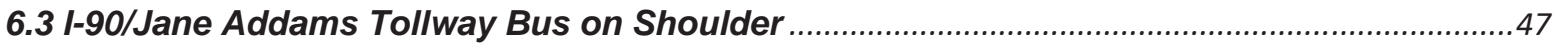

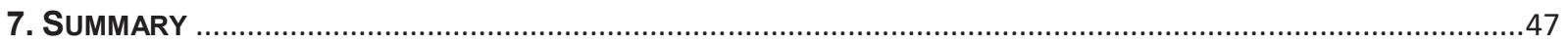

CHAPTER 3. INTERVIEWS WITH STAKEHOLDERS ................................................................................... 49

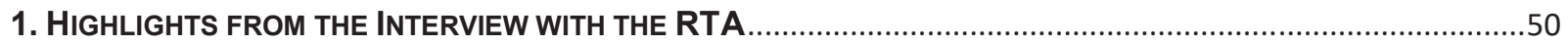

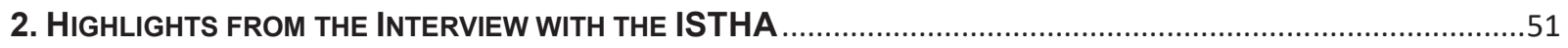

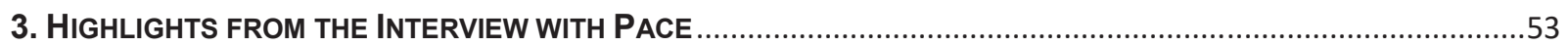

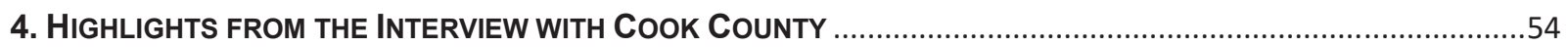

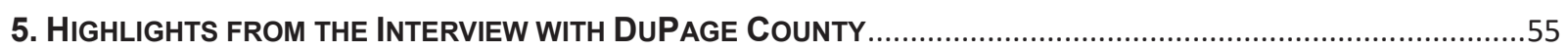

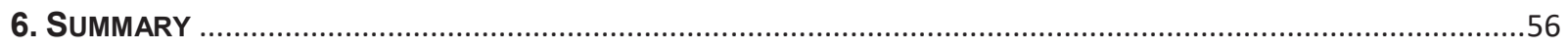

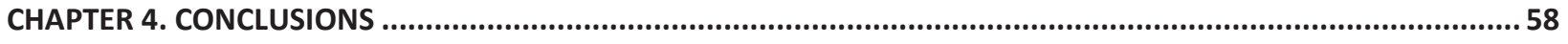

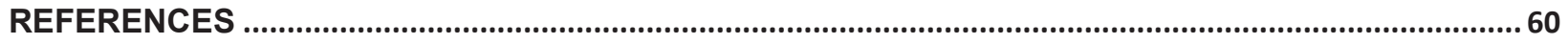




\section{ACKNOWLEDGMENT}

This research was completed through funding provided by the Illinois Department of Transportation (IDOT). This work was supported by the National Center for Transit Research, a program of the Center for Urban Transportation Research at the University of South Florida and funded by the U.S. Department of Transportation. The research team would like to thank transportation officials from the Regional Transportation Authority, Pace, Cook County and DuPage County for their participation in interviews with the research team. The views within this document are those of the authors alone. 


\section{INTRODUCTION}

Mobility management and improvement have become the focal point of the federal, state, and local transportation agencies over the last decade. Even with decreasing vehicle-miles-traveled (VMT) over the same time span, the congestion and delays have not improved leading to a renewed focus on multimodal solutions at all levels. While multimodalism has been part of the transportation vocabulary for a long time, and has been aided by legislation to some extent, it has not been embraced into practice at a large scale. Advances in technology (autonomous vehicles, ridesharing services, transportation network companies, improved dynamic wayfinding systems, as well as improved infrastructure) are providing the paradigm shift needed to look at mobility management in a renewed light. The Greater Chicagoland Northeastern Illinois region is no different from many of the most congested regions in the country, in the sense that the vehicle hours of delay for both passenger and freight are among the highest in the country on an annual basis. This report focuses on this region while drawing on the experiences from other parts of the country to set the stage for detailing the state of multimodal transportation or integrated transportation system in northeastern Illinois.

Due to the high levels of congestion on roadways in northeastern Illinois, it is important to examine ways in which integrating transportation modes may improve mobility in the region. This report first examined integration efforts around the country to gain a broad view of the variety of methods being implemented and an in-depth understanding of some example projects. An examination of both federal and state legislation pertaining to integration provides a starting point from which the region can implement integration techniques. And this report also discusses local integration efforts that are currently being implemented.

\section{CHAPTER 1. LITERATURE REVIEW}

The literature review chapter focused, first, on historical legislation that regarding the history of integration in federal legislation. Secondly, it identified laws and legislation that show the development of integration and multi-modalism in the United States beginning with the Federal-Aid Highway Act of 1962 and continuing to the current federal transportation bill. Thirdly, it uncovered the core tenets of mobility management and the basis upon which it is built. In this regard, the report (a) cross-examined how mobility management overlaps with our established definition and understanding of transportation integration; and (b) examined case studies of mobility management to further illustrate the way that this concept can be connected to transportation integration.

The literature review chapter is organized into five sections. Section 1 examines the arguments for transportation integration, and discusses definitional issues toward a typology of transportation integration in Section 4. Section 2 provides background 
information about transportation integration policy as evolved in federal legislation from 1962 to 2012, and discusses its influence at the state level. Section 3 discusses the conceptual relationship between mobility management and transportation integration, and provides operational examples. Section 4 describes conceptual attributes of integrated transportation systems and discusses implementation examples. Finally, Section 5 discusses institutional barriers, beginning with the federal government, moving through the public sector to local governments before turning its attention to modal challenges, funding, and fare collection.

\section{Why Integrate?}

The integration of transportation systems has great appeal in urban metropolitan areas across passenger transportation modes due to its potential for reducing costs to operators and travelers, lessening environmental impacts, and tying together disconnected urban areas. The benefits of transportation integration are many, and the fact that these systems provide a more sustainable network for movement seems to be an uncontested idea (32). This is especially important given the range of issues that face transportation systems in the coming years. Integrated transportation systems have the ability to change the status quo in regards to transportation's effects in the areas of congestion, pollution, resource consumption, road safety, and public expense (32). The wide variety of benefits related to adopting integrated transportation systems have influence in far more facets of life than the amount of time a traveler may spend stuck in traffic.

The societal implications that result from the establishment of integrated transportation systems may also lead to significant individual benefits. An integrated transportation system that allows users to select from a host of modal options facilitates a series of choices that will result in the lowest user cost for the entirety of the trip (27). On top of the monetary benefits for individual users, integration stands to better the mobility of transportation-disadvantaged populations. The ties between transportation integration and mobility management are strong and both concepts aim to better serve the elderly, disabled, isolated, economically disadvantaged, and communities as a whole (27). Keeping these goals in mind allows the greater system to focus on the needs of individual travelers. By working to coordinate payment systems, schedules, connections between modes, and service provision, transportation systems can once again meet the needs of people above all else (1).

Understanding the goals and benefits of an integrated transportation system allows for easier understanding of the ways in which transportation integration may be defined. The term 'integration' is broadly applied throughout the transportation realm, making it 
difficult to discern a concrete definition of the concept. Drawing from scholarly works, this section seeks to frame a typology for integration for use throughout the remainder of this section.

Using metaphors to describe integration is a helpful way to envision the concept in a more approachable manner. One particularly useful metaphor described by Potter and Skinner is relating transportation integration to a well taken photograph (32). The authors suggest that a successful photograph is made up of three key parts. First, the contents of the image must contain a strong composition concerning the objects and subjects within the picture. Second, the technical aspects used to take the photograph must be correct for the given situation; the equipment used to take the photograph should result in a clear image. Third and finally, the photograph must be taken with some sort of philosophical basis, and the message that the photographer seeks to portray must be clear to the viewer (32). While the direct connections between a well taken photograph and transportation integration may be difficult to discern at first, the key takeaway from this metaphor is the necessity of these three factors working together to create a successful whole. In much the same way, a truly integrated transportation system must contain a functional set of parts that work together and deliver a consistent, efficient experience across modes.

A second metaphor describing transportation integration refers to a large organization's collective computer system (32). This example more thoroughly explains the interconnectedness of various parts within complex transportation systems like those that exist in major urban areas. The metaphor considers a large company that has amassed a variety of separate computer systems over a period of time related to its financial arm. The two examples considered are a pension system and a payroll system, because it would be beneficial if these two separate systems worked with each other. Creating an integrated system out of the two separate parts requires connecting two structures built at different times, likely by different people, and would likely entail a time consuming and expensive effort. In many ways, this metaphor more clearly applies itself to the situation facing the transportation system in urban areas across America. American cities contain different parts of a transportation system that has been constructed over the better part of the last century. Integrating these systems requires costly upgrades and major shifts in organizational structures; things that take great amounts of will and compromise to accomplish.

Potter and Skinner use these metaphors to lay the foundation for their nested definition of integration (32). The first level of integration explained is what they call "functional or modal integration." This idea includes policies that encourage different travel modes to complement each other in facilitating multimodal journeys. The second level of 
integration is considered "transport and planning integration." This entails realizing the close link between land use and transportation planning, and utilizing them in a way to reduce travel demand. Potter and Skinner's third level of integration is labeled "social integration." This idea is defined as including all who have a stake in transportation, from providers to passengers to community members affected by potential noise or odors. The fourth level of the nested definition and highest level of integration is labeled "environmental, economic and transport policy integration." This level involves the combination of the three previous levels of integration in a way that offers the greatest benefit to the entire transportation system.

In his article What's so funny about peace, love, and transport integration, John Preston creates his own hierarchy for defining transportation integration (33). This hierarchy includes seven different levels of integration that may be present within a system. The seven are listed in order of organizational difficulty, as taken from the text (33):

1. The integration of fares, service patterns, terminals/stops, and information within public transport.

2. The integration of infrastructure provision, management, and pricing for public and private transport.

3. The integration of passenger and freight transport.

4. The integration of (transport) authorities.

5. The integration between transport measures and land use planning policies.

6. Integration between general transport policies and the transport policies of the education, healthcare, and social services sectors.

7. The integration between transport policies and policies for the environment and for economic development.

The increasing levels of difficulty between each step are easily understood, and potentially align with the hierarchy proposed by Potter and Skinner. The chart below depicts the relationship between these two perspectives.

\begin{tabular}{|l|l|}
\hline Potter and Skinner (2000) & Preston (2010) \\
\hline $\begin{array}{l}\text { 1. Functional or Model } \\
\text { Integration }\end{array}$ & $\begin{array}{l}\text { 1. The integration of fares, service patterns, } \\
\text { terminals/stops, and information within public } \\
\text { transport. }\end{array}$ \\
\hline & $\begin{array}{l}\text { 2. The integration of infrastructure provision, } \\
\text { management, and pricing for public and private } \\
\text { transport. }\end{array}$ \\
\hline
\end{tabular}




\begin{tabular}{|l|l|}
\hline Potter and Skinner (2000) & Preston (2010) \\
\hline & 3. The integration of passenger and freight transport. \\
\hline $\begin{array}{l}\text { 2. Transport and Planning } \\
\text { Integration }\end{array}$ & 4. The integration of transport authorities. \\
\hline 3. Social Integration & $\begin{array}{l}\text { 5. The integration between general transport policies } \\
\text { and the transport policies of the education, healthcare, } \\
\text { and social services sectors. }\end{array}$ \\
\hline $\begin{array}{l}\text { 6. Integration between transport measures and land } \\
\text { use planning policies. }\end{array}$ \\
\hline $\begin{array}{l}\text { 4. Environmental, } \\
\text { Policy Integration }\end{array}$ & $\begin{array}{l}\text { 7. The integration between transport policies and } \\
\text { policies for the environment and for economic } \\
\text { development. }\end{array}$ \\
\hline
\end{tabular}

Comparing these two hierarchies to other definitions developed by transportation agencies provides further insight into the idea of transportation integration. In Europe, the SPUTNIC Group (Strategies for Public Transport in Cities) defines transportation integration as, "the opportunity to use the entire public transport system across a local or regional area independently of transport modes, tariffs, fares, schedules, ticket systems, etc." (1). Earlier, in the United States, the Intermodal Surface Transportation Efficiency Act, or ISTEA defined integration as, "all forms of transportation in a unified, interconnected manner, including the transportation systems of the future, to reduce energy consumption and air pollution while promoting economic development and supporting the Nation's preeminent position in international commerce" (18).

Having considered these different perspectives on integration, this study has developed the following as a definition for transportation integration moving forward:

Transportation integration allows for seamless movement throughout a transportation network facilitated by a unified system of modes, fares, schedules, and payment systems made possible by coordination and collaboration among the region's stakeholders in pursuit of social, environmental, and economic gains.

This definition will subsequently be broken down into a typology of integration and a more focused definition will be derived for the Northeastern Illinois region specifically. 


\section{Federal Transportation Integration Legislation}

Traditionally, federal transportation policy in the United States has focused on individual modes rather than intermodal systems. Federal funding for surface transportation, passenger rail, and aviation all come from different sources and are established through separate legislation (19). The funding programs for these modes are overseen by different agencies within the U.S. Department of Transportation (USDOT). This concept is commonly referred to as 'siloing' and adds an extra layer of complication to projects that are multimodal in nature.

Early mentions of coordination and multimodal transportation solutions appear in the Federal-Aid Highway Act of 1962. Setting the stage for future efforts, the law states that embracing various modes is necessary to serve States and local communities efficiently and effectively, and that planning for highways should correspond with other affected forms of transportation. The Urban Mass Transportation Act of 1964 continued on the same path set by the Federal-Aid Highway Act of 1962, establishing grant and loan programs to better facilitate planning for multiple modes across a longer period of time. Citing concerns about deteriorating public transportation systems and increasing traffic congestion, this Act required comprehensive planning that by design would incorporate public transportation networks as well as highway networks. A 1962 version of this act specifically contained a reference to the concept of transportation integration, stating that it was a technique that should be used to meet the transportation needs of urban areas across the United States. Continued legislation leading up to the passage of the Intermodal Surface Transportation Efficiency Act (ISTEA) in 1991, adjusted funding requirements and the process through which transportation agencies needed to act in order to receive federal funding. Beyond modal connections, Federal legislation facilitated greater governmental coordination with local agencies and amongst different branches of the Federal government itself. The early efforts towards developing a multimodal transportation system in the Urban Mass Transportation Act of 1964 involved actions to be taken through the Housing and Home Financing Administrator.

With the passing of ISTEA, the United States Government created its first federal policy for a national intermodal transportation system (19). In order to implement this intermodal goal, ISTEA included a set of provisions to help expedite the process for lower levels of government. The list that follows outlines some of the ways that ISTEA facilitated the development of a multimodal system throughout the United States.

- Allowed certain federal highway funds to be used for highway or transit projects.

- Established a set of guidelines to aid metropolitan areas with the prioritization of highway and transit needs to promote integrated systems. 
- Created the USDOT's Office of Intermodalism to aid with additional federal policies on intermodalism.

- Created the Intermodal Transportation Advisory Council to provide recommendations on how to best coordinate federal policy.

- Required the formation of a National Commission of Intermodal Transportation to create a report and make recommendations to achieve the national integration goal.

- Required states to develop and implement six management systems for managing highway pavement, bridges, highway safety, traffic congestion, public transportation facilities and equipment, and intermodal transportation facilities and systems (19).

ISTEA was the first federal surface transportation bill to be passed since the Federal Aid Highway Act of 1982. It created the nation's first intermodal goal, helped broaden the planning activities of State DOTs to include a variety of modes, and increased efforts towards interagency coordination (50). With the promise of a national intermodal system that seemed to be a part of ISTEA, the question remains: why does a system like this not exist today?

In 1994, the National Commission of Intermodal Transportation published their mandated report of recommendations to improve the United States' intermodal transportation system. This report created three sets of recommendations addressing investment and funding issues, synergistic transportation mode policies, and perhaps most importantly, the need to restructure government institutions to improve intermodal transportation (27). Institutions in the Federal Government at the time were set up to focus on individual modes, with each of them being responsible for their own projects, funding, and planning. Because of this organizational method, it was difficult for separate institutions to coordinate because of funding complications and project timelines. To solve the problem, the USDOT attempted to reorganize and streamline its operating administrations in an attempt to achieve the goal of a national intermodal system (27). In 1995, the USDOT proposed a bill to Congress to consolidate their institutions to three operating administrations: Surface, Aviation, and Coast Guard. Congress ultimately set the proposal aside and the existing structure of the USDOT remained. In subsequent years several other surface transportation bills have been passed containing many of the provisions and requirements established in ISTEA; however, little development has occurred since. A Transportation Research Board report published in 2003 concluded that the goal of a national intermodal transportation system would be appropriate, but is considered to be too broad to attain through the limited means available through the federal surface transportation act or any other single federal program (19). 
In February of 2004, President George W. Bush issued Executive Order 13330 on the topic of human service transportation. The order recognized the fundamental importance of human service transportation, the ongoing need to enhance coordination, and directed a plethora of federal departments and agencies to collaborate and ensure that transportation services are seamless, comprehensive and accessible (36). The term human service transportation refers to meeting the basic and day to day transportation needs of underserved communities, often including groups of low income, disabled, and older individuals. Many human service transportation programs include dedicated buses and vans as well as programs that provide assistance for relevant transportation planning initiatives and reimburse individuals and groups for public transit use, vehicle upgrades, and gas costs. The past two decades have featured significant investment in special public transportation services; however, there are still major gaps in services and many individuals have difficulty meeting their basic transportation needs (36). The executive order also established the Interagency Transportation Coordinating Council on Access and Mobility (CCAM). CCAM was responsible for identifying legislative and administrative actions, throughout all levels of government that were useful in coordinating human service transportation, identifying federal rules and restrictions that limit coordination, reducing service duplication to free up further funding, and to make recommendations that would advance the principles of the executive order (36). There were five broad recommendations made by CCAM, of which the most relevant to this study focused on coordinated transportation planning. This recommendation promoted coordinated transportation services through a series of mechanisms that could be used to require community participation in the planning process for human service transportation programs (36).

As a precursor to President Bush's executive order, the FTA established a program through the 1998 federal transportation bill, Transportation Equity Act for the 21st Century (TEA-21), called the Job Access and Reverse Commute program (JARC). The JARC program was initially created to address transportation barriers that affect low income individuals and help close the funding gaps for the welfare to work program (52). Under TEA-21, the JARC program established three types of partnerships (planning, financial, and operating) for organizations desiring to apply for and use funding. Planning partners generally consisted of government agencies, faith-based organizations, and nonprofits that are responsible for aiding the planning process by creating an Area-Wide Job Access and Reverse Commute Transportation Plan (JARCTP). These stakeholders were also involved in overseeing JARC activity in their respective regions. Financial partners are responsible for helping match 50 percent of the funds from non- DOT sources, and the organizations and service providers, usually 
public transit agencies and private transportation providers that operate the services funded by JARC funding are the operating partners (52).

The passage of Safe, Accountable, Flexible, Efficient Transportation Equity Act: A Legacy for Users (SAFETEA-LU) in 2005 brought about several changes to the existing JARC program. One of the largest changes was a modification changing the old funding program to a formula grant program. This system distributed 40 percent of JARC funds to small urbanized and rural areas and 60 percent to large urbanized areas, reaching more states and areas than ever before (11). SAFETEA-LU also required a coordinated Human Services Transportation Plan (HSTP) for all of the FTA human service transportation programs, which included JARC, New Freedom, and Elderly Individuals and Individuals with Disabilities Program (52). The purpose of the HSTP was to certify that communities coordinated all of their transportation resources and funding sources provided by several different federal programs. The HSTP planning process was required to be heavily oriented toward public participation, and also included representatives of human service, public, private, and nonprofit transportation providers. The plan also was required to include goals that addressed the transportation needs of individuals with limited mobility options, and could either be developed independently or incorporated into the statewide and metropolitan planning processes (52). The HSTP assisted in the coordination process, bringing together a variety of agencies, and providing new perspectives and resources from organizations that did not typically work together; however, there were many challenges that made the process difficult.

The JARC program was a major funding program that exposed several of these coordination difficulties. The JARC program received a small amount of funding compared to other transit programs, yet there were still strict regulations that needed to be met in order to obtain funds (11). According to a GAO report on the JARC program, challenges to coordination existed because of a lack of sufficient funds, resources and expertise, and difficulties in engaging human service agencies (11). One of the limitations of the program was that the allotted funding for administrative and planning functions often fell short. The ten percent of funds available for these tasks was often insufficient to cover the cost of required planning. Many states have struggled with financing the development of HSTPs, because the grant program funding does not cover the cost of a consultant or of internal staff work. Rural areas, in particular, face a range of difficulties when attempting to develop HSTPs. Many of these areas do not have the staff or the proper regional planning framework needed to suitably complete the necessary requirements, negating them from being possible fund recipients (11). Another issue facing coordination is the difficulty of trying to consistently engage with and incorporate other organizations in the planning process. Many human service agencies may not participate or consistently participate in the planning process, 
because there is a relatively small amount of funding available offering little incentive for their time (11). Many of these difficulties were brought to plain sight and addressed in the drafting of the new federal transportation bill, the Moving Ahead for Progress in the 21st Century Act (MAP-21) of 2012.

MAP-21 ultimately repealed the JARC and New Freedom grant programs, and consolidated their funding sources into three existing programs: the Enhanced Mobility of Seniors and Individuals with Disabilities, Urbanized Area, and Rural Area Formula Grant programs (41). The consolidation of these programs attempts to correct many of the coordination issues that occurred in SAFETEA-LU by addressing it on a more categorical level. The Urbanized Area and Rural Area Formula Grant programs each encompass their designated areas, allowing for requirements to be more specified and easier to obtain. The Enhanced Mobility of Seniors and Individuals with Disabilities grant program operates in a similar fashion, and absorbs and consolidates many of the New Freedom program eligibilities into a single formula program (41). MAP-21 is a fairly new transportation bill, so little can be discussed pertaining to how it has affected funding; however, the changes and consolidations made to the JARC and New Freedom programs provide a promising future for transportation integration across all levels of government.

These legislative initiatives have encouraged the adoption of integrated practices at various levels of government across the United States. Efforts toward integration can be seen in some long term planning initiatives that are produced by either State Departments of Transportation or Metropolitan Planning Organizations. Two key themes emerged after a review of these plans. First, plans are more likely to include ideas related to integration if there is state level guidance encouraging integration. The long range planning documents from Miami, Tampa Bay, and Orlando's MPOs all reference the Florida Strategic Intermodal Systems Plan (SIS) as part of their document. The SIS was created by the legislature and governor of Florida in 2003 under the pretense of improving economic competitiveness, and incorporates the transportation facilities on which 99 percent of travel occurs (58).

The 2035 Michigan Transportation Plan was the only statewide planning document that was in the top tier of documents that spoke to efforts towards integration. It includes links to a number of different policy documents and white papers which serve to direct MPOs and other organizations to the types of planning and development that the DOT encourages. This includes a specific white paper on Policy Initiatives and Integration (23). Some of the initiatives proposed in this document include intermodal transit centers, increased intercity bus service, regional transit proposals, and transportation alternatives for commuters (24). The advances seen in this document is reflected in the 
Grand Valley Metropolitan Council (Grand Rapids, MI)'s 2035 Long Range Plan, illustrating the ways that state-level guidance can influence the development of integrated practices. A more detailed examination of the state of integration efforts in Michigan is presented below in the case study portion of this document.

\section{Mobility Management and Transportation Integration}

As mentioned earlier in this report, mobility management and integrated transportation systems are two highly connected topics. This section seeks to develop a common understanding of mobility management as it will be used in this study before comparing the ways that mobility management and transportation integration seek to address challenges in current transportation systems.

At its very core, mobility management can be thought of as placing the needs and desires of individual people ahead of other considerations in providing transportation services (including thinking of passengers in terms of masses to be moved) (5). This is especially true in the case of large transit providers, who under the premise of mobility management are encouraged to think about the needs of individual people across the transportation spectrum rather than just the assets that they own or control (49). Proponents of mobility management understand that achieving this highly idealistic goal is not easy and provide a number of challenges along with potential solutions to overcome them. In terms of modal barriers, mobility management seeks to consider all options for travel, not only the single passenger automobile and traditional mass transit service (5). Mobility management thinking includes reviewing both tangible and theoretical solutions to those facing mobility challenges. The theoretical side includes both a focus on individual needs over perceived generalizations about wider society as well as encouraging "innovation" in the transportation realm. More tangible initiatives include facilitating interagency coordination and working to develop single points of access to the transportation network for travelers (5).

The concept of mobility management includes three basic premises as described by Burkhardt and McLary (5). The first of these is providing information and informing travelers about transportation options that are available to them (5). This is done regardless of mode or provider. The aim is to provide the traveler with all available options so that they may make a choice that serves their needs best by facilitating communication and coordination among traditional transportation providers along with social services providers, business and industry leaders, and non-traditional providers (49). The second basic function is making trip connections by brokering trips for customers among the available service providers (5). Again, this focuses on facilitating interagency coordination and trips that span across available modes. Working and 
thinking across modes is of particular importance to the mobility management conversation as most motorized transportation modes involve non-motorized modes at either the entrance or egress point of a journey (21). Third and finally, mobility management focuses on the role of transportation planning within communities (5). This function seeks to maintain a connection between transportation and land use planning, and to ensure the availability of transportation functions for residents of a community.

The relationship between mobility management and transportation integration can be investigated by comparing both concepts on the grounds of the three functions discussed by Burkhardt and McLary (5). In terms of information sharing, mobility management dictates that information should be provided across modal barriers, while facilitating communication and coordination between traditional and non-traditional transportation providers. Transportation integration focuses on the utilization of intelligent transportation systems to share information and develop multimodal networks while providing seamless service within a given geographic area.

Facilitating connections between different communities and modes of transportation is a focus of both mobility management and transportation integration. The mobility management literature comments on the need to broker trips between service providers and create connections for travelers themselves rather than the system. Transportation integration places an emphasis on creating more seamless physical transfer points that allow travelers to shift modes with greater ease and on facilitating inter-agency coordination and cooperation.

Community roles are also a point of comparison between the two concepts. While mobility management stresses that the focus should be on people first, rather than other issues, transportation integration places an emphasis on providing a transportation system that is simple and efficient from a supplier perspective.

The concept of mobility management regarding access to information, facilitating connections, and playing a role within communities is similar, but not exactly identical to how the transportation integration literature proposes to address these topics. Both work towards developing a transportation system to better serve communities in different ways. It is important to understand that although mobility management and transportation integration are not identical policy initiatives, they also need not be seen as conflicting ideals that compete with one another. The two ideas can and should work together to facilitate the creation of a transportation system that provides benefits and greater efficiency to transportation providers, regional infrastructure, and travelers. The United We Ride program, initiated by the Coordinating Council on Access and Mobility (CCAM) in 2004, is a good example of how both mobility management and 
transportation integration can work together to improve the transportation system. According to a brochure published by United We Ride, mobility management is "an innovative approach for managing and delivering coordinated transportation services to customers, including older adults, people with disabilities, and individuals with lower incomes" (55). One of the primary goals, like the ideas discussed above, is the coordination of services to achieve a transportation system that is most efficient for providers, travelers, and taxpayers. The United We Ride program emphasizes the development of transportation systems that work across service boundaries and modal divisions to craft a travel network that will best serve the people who rely on transit for their mobility needs. When programs like these are combined with efforts to simplify transfers, fare structures, tolling, and the like, the greater transportation system sees benefits for all involved. This is how the combination of integration and mobility management could be viewed in practice.

Reviewing case studies of mobility management programs in European communities also provides insight into how mobility management and transportation integration policies can work together. This is beneficial as European communities frequently have transportation systems with higher levels of integration than their American counterparts. The demonstration projects conducted by the MOST mobility management program in Europe focused on sectors of society including educational institutions, tourism, health institutions, site development, temporary sites, and mobility centers while also seeking to reduce the environmental impacts of transportation (58). All of these initiatives aimed to somehow improve transportation service for a group of people who were currently underserved by the existing system. In this way, the mobility management initiatives worked to help aid the improvements in integration already present within each of the different European test markets.

Another review of mobility management initiatives in Rome, Italy, analyzed the effects of a mobility management initiative that aimed to reduce the city's growing dependence on the single-occupancy automobile or motorcycle for its transportation needs. This was added to pre-existing integration programs that had been started to improve public transport in an attempt to reduce the number of private cars, citing pollution and congestion concerns (26). As such, the Roman model took on a decidedly anti-car position that would be extremely difficult to implement in the United States. Despite this fact, some of the policies introduced as part of the program seem to have potential in a more auto-oriented community. These included hiring nearly 200 mobility managers to plan home-to-work trip options for over 250,000 employees, and a variety of incentives including discounts for transit tickets and kickbacks to employees of corporations that signed on to mobility manager-organized shuttle services (26). Mobility management policies like these were implemented on top of other initiatives that aimed to develop a more integrated transit system, if not one that worked to limit or even eliminate the 
prominence of the single passenger vehicle. This included implementing carsharing measures, studying carpooling habits, and further developing a clean transit fleet (26). A review of these policies found that the mobility management initiatives would result in increased public support of sustainable modes by $25 \%(26)$. It is conceivable that this support would not be limited to those modes incorporated in the mobility management program (employer shuttles, vanpools, etc.), but also to other alternative transportation modes. Improving the public perception of sustainable modes may have effects across the board as the dominant mode of transportation within the society shifts from the automobile or motorbike to some sort of publicly supported transportation.

\section{Types of Transportation Integration}

The majority of passengers in America today commute to work as single occupants in their own vehicles, rather than using transit or other non-automobile modes. An individual's conceptualization of travel cost plays a large role in this decision. Transit is often only considered for a trip if driving is deemed too costly (19). Although there are many factors that are associated with the cost of driving, there are two that seem to affect a person's travel behavior most greatly: congestion and land use. Congestion affects travel mainly in terms of time; the more time wasted sitting in traffic the worse off an individual tends to be. Land use and transportation options can greatly influence travel decisions. For example, a person who lives in a dense mixed-use area with available transportation alternatives, such as transit or bicycle and pedestrian infrastructure, would be more likely to take transit and not drive because it may be cheaper and possibly more convenient (4). This concept of switching from driving to the use of transit or other modes heavily relies on having an effective integrated transit system. If passengers can easily use a series of transportation modes to get to their destination, and it is quicker and less expensive, they will ultimately choose that form of travel (19).

An effective integrated transportation system has the ability to connect to an extended transportation network, is reliable, and provides seamless transfers between modes. It can be achieved through the successful planning and implementation of intermodal projects through coordinated efforts of state, local, and private stakeholders. Integrated systems are typically developed by state or local transportation agencies, but state departments of transportation and metropolitan planning organizations can often partake in the process as well (19).

Integrated transportation systems are not created overnight and often can be quite complicated. When planning an integrated system for a city, some of the most important decisions are the selection of modes and the roles they will play as a part of the system. 
According to Vuchic's book, Transportation for Livable Cities, there are 4 types of integrated systems: unimodal, multimodal, intermodal, and balanced (57). A unimodal system focuses on one primary mode of transportation, with all others taking on more trivial roles. This system is often seen in strictly auto-oriented environments, where the automobile is the dominant mode and is essentially required for all travel. A multimodal system refers to a system that has several modes that operate within a city or metropolitan area. These modes may or may not be integrated, and there is little to no coordination or planning among service providers. An intermodal system is a step up from a multimodal system still consisting of multiple modes, but they are integrated together to increase the efficiency of transit trips. This type of system usually involves schedule and network coordination, as well as fare system integration and shared information networks. The last and highest classification of an integrated transportation system is a balanced system. This system is an intermodal system in which each mode reaches its most optimal and efficient purpose. Passenger convenience, comfort, and overall efficiency of the system are maximized in this scenario (57).

Integration can also be broken down into several major components including coordination, fare integration, and information integration. Coordination and integration are two terms that virtually go hand in hand with one another. If transportation agencies, service providers, and other stakeholders do not coordinate with one another, an integrated system cannot come to fruition. According to Sørensen and Longva there are four categories of coordination: organizational, contractual, partnerships, and discursive (45). Organizational coordination is an increase in coordination by changing organizational structures. Two examples of this include creating joint working groups between two entities or merging several organizations into one entity. Contractual coordination refers to coordination being addressed directly through a contractual agreement between groups. This form of coordination is legally binding and usually involves some sort of a penalty if obligations are not met. There are many examples of this in the transit world, including contract agreements between transit agencies and DOTs related to services and funding. Partnership coordination is considered a relationship between two parties, formal or informal, where there are no penalties or requirements involved. This is most often exemplified through meetings between two agencies, or one group providing another with information. Discursive coordination is a method that tries to achieve coordination through changing negative impressions and verbally emphasizing the need for coordination. This method is often used when addressing a regional problem, for example, a transit agency publicizes the poor conditions of an area's regional rail network and tries to get others involved to help (45).

In the United States, coordination and collaboration have improved in the last few decades due to federal requirements in the Intermodal Surface Transportation 
Efficiency Act (ISTEA). ISTEA requires DOTs to collaborate with their MPOs to develop comprehensive and multimodal plans; however, there still seems to be a lack of coordination between various levels of government and organizations (50). According to Taylor and Schweitzer there are several coordination issues involving agencies in the United States (50). The first of these issues is that there is rarely a consensus on transportation priorities at the state or regional level. There is often a lack of consistency between statewide goals and regional plans, sometimes because regional plans are more focused and context-specific, but also because regional planners tend to not refer to statewide plans when they are creating their own plan. In the study, most states were found to have positive and cooperative relationships with regional partners and stakeholders, but problems with coordination tend to arise during project management activities and implementation phases (50). Coordination plays a vital role in the transportation planning process but it is also incorporated in many other aspects of the transportation integration process.

The integration of fare and tariff systems is another key part of the integration process. There are several types of fare integration including mutual acceptance of tickets on the same route, mutual acceptance of tickets within the same network, and tariff unions. The simplest level of fare integration is the mutual acceptance of tickets on the same route. This allows operators of different services to accept the same ticket from passengers for a given trip (1). An example of this can be seen through a commuting process to a popular destination that requires multiple modes. Single tickets can be sold that allow passengers to take a train to a certain place and transfer to a bus to take them to their final destination. This method does not need a complex fare system to be implemented; however, it typically can only be put into place if the service providers involved have the same amount of riders, otherwise complications can occur and additional compensation may be necessary (1). This type of integration works best on a case by case basis and is not usually adequate at a regional scale.

The next type of fare integration is the mutual acceptance of tickets within the same network. This type of integration is a slight step up from the previous method, as tickets can be used across an entire transportation network instead of just on one route. A series of tickets can be used to help riders seamlessly transfer from one mode to the next to get to their final destination (1). This method focuses on not only coordinating fares and tickets between operators, but also possibly coordinating timetables of different modes, so transfers can be made easily.

The most complex type of fare integration is the tariff union. In this method, all transportation operators of a system establish a tariff for a region or regional zones. Users of the system can buy a ticket from one zone to the zone their destination is in 
and take any multitude of transportation modes they prefer, within those areas, all with one ticket. There are two types of tariff unions that are typically seen: season pass tariff unions and integrated tariff unions. A season pass tariff union refers to a monthly or annual pass that a user can buy that allows them to take any mode of transit available in a designated area (1). This type benefits regular users of the transit system and can often generate an increase in ridership across the spectrum from irregular users to season pass users. Integrated tariff unions are very similar to season pass tariff unions except they allow season passes and single/multi-trip tickets to be used on all available modes in an area. This type of fare integration not only satisfies everyday users, but also promotes the use of the transit system to tourists and visitors (1).

The integration of information sources is another important part of the integration process. By developing a single way of delivering information for multiple agencies, the system's existing and potential users can be more informed about transit trip planning, and real time information involving transportation conditions including transit/traffic delays, incidents, and arrival times (25). Trip itinerary planning is often something that is accomplished through the use of an integrated website or online tool. With a common source of information for all the agencies in a region, it is much easier for users to plan trips and learn about local transit options (38). One of the more recent developments in the integration of information is the availability of real time information in the form of Integrated Corridor Management (ICM) systems.

Integrated Corridor Management (ICM) Systems reflect the use of information technology to create a transportation system that uses data sharing and modeling to inform travelers about different options for completing their trip. An ICM as defined by the U.S. Department of Transportation includes providing real-time information, coordinated multimodal operations, and the use of technology to alleviate congestion (2). To achieve these aims, the ICM program has three key objectives (2). First, the ICM initiative will demonstrate how technology can help aide the movement of people and goods. Second, the program will develop a toolbox of operational policies, crossnetwork operational strategies, integration, requirements, and methods and analysis methods to implement these systems in the future. Third and finally, the program will demonstrate how intelligent transportation technologies can be used to coordinate operations between different corridor networks and increase the efficiency of a corridor's capacity. The development of these programs is extraordinarily data-hungry and requires coordination between all transportation related agencies along a given corridor. All of this data is then used in a centralized system that produces models to inform travelers about modal options for completing their journeys.

The concept of an Integrated Corridor Management System is best illustrated through 
one of the pilot projects that has been funded by the ICM program. The U.S. Highway 75 corridor in the Dallas metropolitan area paints a clear picture of how an ICM project would come to fruition. The US-75 corridor features high-occupancy vehicle lanes, light rail transit, bus service, and park and ride lots (8). All of these services provide shared data into a centralized data warehouse that is used to develop the models that provide information that is then distributed to travelers along the corridor. The data is then used within a "decision support system" that, through modeling, estimates the amount of time to a given destination (2). Further functionality from the decision support system can be seen in incident responses. The system has the capacity to send out alerts to participating agencies regarding incidents that have occurred on any of the participating networks so that services may be altered to best facilitate travel within the corridor (2).

At the core of an ICM system is the interaction between automobiles and transit. Park and rides are one method through which automobile travel is integrated with other transportation modes in the United States. Park and rides first began appearing in the United States during the 1930s and were by and large an ad hoc practice in locations near bus or rail stations along the urban fringes (30). The concept of park and ride facilities has developed since then. Eventually, the process was formalized with one early example being a facility along the Long Island Railroad in 1939 on the site of the World's Fair (30). The practice of implementing formal park and ride facilities has continued in the decades since, resulting in park and ride becoming a familiar term in transportation circles. In the late 1960s through the 1970s, federal programs sped up the development of park and ride facilities by providing direct funding or allowing highway funds to be used for facility construction (30). Further policy developments occurred through subsequent years at the federal, state, and local levels. As of 1988, more than 36 cities in the United States were home to park and ride facilities (30). Generally speaking, the cities most inclined to invest in park and rides are those in either large traditional metropolitan areas like Boston or Washington, or those with low transit ridership, like Los Angeles or San Diego (9). Two cities that fall into these categories, San Diego and Dallas, are currently participating in the Research and Innovative Technology Administration (RITA) directed pilot project studying the potential impacts of Integrated Corridor Management Systems as described earlier. As such, they provide an interesting opportunity to observe the potential impacts of weaving park and rides into a "smart corridor" system.

Another potential avenue for integration between automobiles and transit is through innovative concepts like smart parking systems. The basic premise of smart parking allows for the use of advanced information technologies to help motorists locate, reserve, and pay for parking (39). The tangible outcomes of smart parking include informational signage along freeways informing motorists of available parking spaces 
and comparative travel times between transit and the roadway, apps that allow travelers to reserve or pay for spaces, and payment systems that could be used for both parking and transit fare payment (14). A trial of a smart parking system was conducted by MTC at the Rockridge BART station in Oakland, California. The system utilized remote reservation and payment along with informational signage along nearby Highway 24 (39). This work was followed by a trial of smart parking at park and rides along the COASTER commuter rail in the San Diego metropolitan area. The San Diego trial included implementation at six different stations and included surveys of riders to gather their impressions of the smart parking system (40).

For any of these methods of integration to work, there must be underlying organizational coordination to guide policy and shape the direction of these systems. The examples of smart parking integrated with park and ride systems offer some clues into the types of agencies that are often involved in these kinds of projects. In the San Francisco case those involved in the project included Caltrans, BART, California Partners for Advanced Transit and Highways (UC Berkeley), Parking Camera, Inc., Quixote Corporation, Intel, and Microsoft (39). These groups represent public agencies at both state and regional levels, a research center, and private sector firms. The San Diego case (which was developed using the ideas from the San Francisco case) involved a similar group of stakeholders. Those that were carried over from the previous study included Caltrans, UC Berkeley and ParkingCarma, while new participants included the San Diego Association of Governments, the North County Transit District, and the FHS's Value Pricing Pilot Program (40). Both of these cases demonstrate the complexity (in terms of stakeholders) that must be overcome to implement an integrated smart parking system, and the amount of work that would likely be necessary to mimic the process in other metropolitan areas.

\section{Barriers and Opportunities for Transportation Integration}

Transportation system integration, as described in the earlier sections of this review, requires overcoming a series of obstacles. These include institutional barriers between governments and agencies, infrastructure and modal barriers, funding discrepancies, and fare collection challenges. Each of these challenges adds an extra layer of difficulty to achieving an integrated transportation system. Despite this, the literature suggests that these historically-entrenched obstacles have provided opportunities to build stronger, more integrated transportation systems. The methods used to overcome these challenges serve as examples for other regions struggling to rise above the issues that stand in front of them. This section will first assess institutional barriers, beginning with the federal government, moving through the public sector to local governments before turning its attention to modal challenges, funding, and fare collection. 
Coordination between entities within the Federal government has been an obstacle to creating an integrated transportation system for years. The GAO report titled "INTERMODAL TRANSPORTATION: DOT Could Take Further Actions to Address Intermodal Barriers" (19) investigates the institutional challenges to creating an integrated system. The first issue raised within this report is the way in which the USDOT is organized. Operating administrations within the DOT are separated by mode, making joint efforts towards intermodal or integrated operations far more difficult than focusing on a single mode (19). This results in many projects focusing on only one mode at a time, rather than considering the range of modal options that may exist within a given corridor. Further challenges appear when one considers the fact that each modal unit at the USDOT has different criteria or eligibility requirements for projects, making planning and implementation of multimodal projects difficult (19).

Barriers within the DOT are not the only institutional challenges that must be overcome to develop an integrated transportation network. The relative lack of resources available for the evaluation of intermodal projects makes it difficult for State DOTs and MPOs to quantify benefits to the nation at large rather than at the local or regional level. Local and state governments may also only have the technical know-how or capacity to evaluate tradeoffs within one mode of transportation rather than a multimodal transportation network.

Disconnects do not only appear in relation to the Federal branch of the government. According to a study conducted by Taylor and Schweitzer, about seventeen percent of surveyed regional planners reported actually looking at their statewide transportation plans during their day to day planning work (50). Interestingly enough, this disconnect does not reflect a poor working relationship between State DOTs and MPOs. In fact, the opposite is true; agencies that were interviewed as part of the study reported that, on the whole, they had good working relationships with their state DOTs (50).

Local governments face a unique set of challenges when attempting to coordinate in working towards an integrated transportation system. A case study of a bridge project in the Louisville metropolitan area conducted after the passage of ISTEA provides some insight into the obstacles that still remain, even under the pretense of legislation that aims to facilitate collaboration. Both ISTEA and TEA-21 aim to encourage the assessing of a number of different alternatives to a project and reviewing them for multimodal compatibility (56). The author's study of this project in Louisville exposed some of the longstanding challenges present at the local level. The study found that the many governments and agencies involved in the project knew from the beginning the development option that they wanted to see take place; this effectively made the alternative analysis process irrelevant (35). This lack of willingness to communicate was 
reflected in the end result of the planning process. The authors state that in the end, the project was carried out in an undesirable way, mostly as a result of massive communication failures (56).

Another case study of local government coordination, albeit with a more successful ending, discusses the creation of the Greater Vancouver Transportation Authority (GVTA). While this study focuses more on the public transit sector, it contains lessons that can be applied to entire regional transportation systems. The challenges facing the system before the creation of the GVTA included a suburban versus urban mentality, and difficulty coordinating public and private transportation providers (22). Through a long process of negotiation, the GVTA was established. In a review of the process, the author notes that even in the case of a success story like this, some key players are still missing including a representative from the airport and port system (22).

The involvement of private organizations in the transportation sphere provides further opportunities for coordination and integration. A review of public transportation provision in Melbourne, Australia demonstrates how public and private entities can work together to help create a more integrated transportation system. All bus service in Melbourne is provided by private operators (48). This adds a new layer to the traditional transportation planning process. When the Victoria Government in Australia began working to develop an integrated transportation plan for the Melbourne region, the private operators played a key role (48). Rather than being seen as a burden, the presence of these private firms was accepted as an asset to the planning process. Private firms in the area were tasked with conducting research projects regarding service provision and transit disadvantaged populations; the findings of these studies would help in plan development as well as in assessing future business models (48). According to the author, coordination can also be encouraged through contractual relationships between the public and private sectors. The contracts that were developed through this integration planning process included performance indicators, not just for the private operators, but also for the public agency in charge of oversight (48). This places an emphasis on fairness and mutual respect between the two parties.

Hurdles to achieving an integrated system not only come from the policy side of the transportation equation, but also from the existing physical infrastructure. One of the most challenging obstacles to overcome in establishing an integrated system is making transfers between modes less costly for travelers in both a monetary and time sense. Guo and Wilson studied the London Underground in working to better understand the way that people perceive transfers. This study produced a number of key obstacles to developing integrated transportation systems. These include a lack of cohesion between organizations providing transit service, difficulty planning for transfers when 
they are frequently the result of overlapping components of previously implemented plans and ideas, and a lack of tools to fully understand what a transfer entails and what its effect may be (12). The fact that these obstacles were derived from a system that only features one mode speaks to the effect that these issues would have in other transportation systems. It is entirely likely that applying these same barriers to a multimodal system would magnify their effects; these issues can be mitigated through better facility design and schedule coordination (12).

Barriers to integrated transportation systems can also occur through a lack of walkable infrastructure between modes. Pedestrian connectivity to all modes is of prominent importance in designing a truly integrated transportation experience across an entire urban area (46). In particular, a walkable environment is conducive to transit systems that can be better integrated. In order to maximize this type of integration, transit stops should be between $1 / 4$ and $1 / 2$ mile apart from each other (46).

Infrastructure and modal barriers can also create a social type of barrier called passenger inconvenience. The notion of passenger inconvenience is directly related to time. The longer a passenger's trip is the more unattractive it becomes. There are several elements associated with passenger inconvenience including mode and station transfers, lengthy layovers and waiting periods, the purchase of separate tickets, and the availability of schedule information (35). As mentioned previously, the ability to seamlessly transfer from one mode to the next is one of the most important aspects of an integrated transportation system. Sometimes transfers are not immediately available or are at a different station/facility. In this instance, the passenger has to spend time traveling to a different location or wait for their other mode of transportation to arrive, creating a dwell time. The longer the dwell time, the more inconvenient it becomes for the passenger, giving them a lower quality transportation experience and possibly discouraging their future use of the transportation system (35). Another common passenger inconvenience is the purchase of separate tickets. Individuals are much more likely to ride transit if all they need is a single ticket to make a trip, regardless of how many transfers or mode changes occurred. This concept can also be applied to the availability of schedule information. If schedule information for all modes of a transit system is located in one location, passengers will be better informed and more likely to use transit (35).

Funding difficulties pose one of the greatest challenges of all to achieving an integrated transportation system. A study by the National Cooperative Highway Research Program of existing ICM programs found that even those programs that are successful are in danger because of a lack of long term funds (59). Up until the passage of ISTEA, funding provided by the Federal government was inflexible, and needed to be used for 
the project or mode for which it was designated (19). Over the years, this policy has gradually changed to allow for greater flexibility. ISTEA began allowing for more local control of how these funds were used, better facilitating multimodal projects (19).

Specific categories of funding can be applied to multimodal transportation projects. The first of these is the Transportation Infrastructure Finance and Innovation Act of 1998, or, TIFIA. TIFIA provides federal credit assistance for surface transportation projects, including passenger bus and rail facilities, by covering up to 33 percent of eligible project costs (19). To receive money from this program, local governments must generate a revenue stream based on user charges. A second program that provides funding for multimodal transportation improvements is the Congestion Mitigation and Air Quality Improvement program, or CMAQ. Any project working towards intermodalism is eligible for funds, but must compete head to head with single mode projects. Third, the FTA New Starts program provides funding for airport and rail system projects, offering a portion of funds needed to complete a given project. A fourth available program to help further efforts towards integration is the Projects of National and Regional Significance program. Projects are eligible for funding through this process if they provide benefits at a national or regional level (19). These benefits may include economic productivity, facilitating intermodal trade, relieving congestion, or improving safety. Fifth and finally, the Freight Intermodal Distribution Pilot Grant Program makes funds available directly to intermodal programs as a part of the SAFETEA-LU legislation and funding remains available until expended under MAP-21. Importantly, TIFIA, CMAQ, and New Starts continue to be authorized under MAP-21.

\section{Summary}

The previous literature review examined tangible issues regarding integration of transportation systems. The list below summarizes the major findings:

- Transportation systems integration has the potential for reducing costs to operators and travelers, lessening environmental impacts, and tying together disconnected urban areas, thereby providing a more sustainable network for movement of people and goods.

- Transportation systems integration can be defined by two corresponding conceptual frameworks in a series of steps of increasing level of implementation difficulty as follows: 


\begin{tabular}{|l|l|}
\hline Potter and Skinner (2000) & Preston (2010) \\
\hline $\begin{array}{l}\text { 1. Functional or Model } \\
\text { Integration }\end{array}$ & $\begin{array}{l}\text { 1. The integration of fares, service patterns, } \\
\text { terminals/stops, and information within public } \\
\text { transport. }\end{array}$ \\
\hline & $\begin{array}{l}\text { 2. The integration of infrastructure provision, } \\
\text { management, and pricing for public and private } \\
\text { transport. }\end{array}$ \\
\hline $\begin{array}{l}\text { 2. Transport and Planning } \\
\text { Integration }\end{array}$ & $\begin{array}{l}\text { 3. The integration of passenger and freight } \\
\text { transport. }\end{array}$ \\
\hline 3. Social Integration & $\begin{array}{l}\text { 5. The integration between general transport } \\
\text { policies and the transport policies of the } \\
\text { education, healthcare, and social services } \\
\text { sectors. }\end{array}$ \\
\hline $\begin{array}{l}\text { 4. Environmental, } \\
\text { Economic, and Transport } \\
\text { Policy Integration }\end{array}$ & $\begin{array}{l}\text { 6. Integration between transport measures and } \\
\text { land use planning policies. } \\
\text { policies for the environment and for economic } \\
\text { development. }\end{array}$ \\
\hline
\end{tabular}

- Legislative initiatives at the federal level have encouraged the adoption of integrated practices at various levels of government across the United States.

- Developing a common understanding between mobility management and transportation systems integration can help addressing challenges in current transportation systems.

- Transportation systems integration can, ideally, lead to a "balanced" system, an intermodal system in which each mode reaches its most optimal and efficient purpose in order to maximize passenger convenience and comfort, as well as overall system efficiency.

- Integrated corridor management systems employ information technology to create a transportation system that uses data sharing and modeling to inform travelers about different options for completing their trip.

- Institutional barriers between governments and agencies, infrastructure and modal barriers, funding discrepancies, and fare collection challenges are critical issues to address toward realizing transportation systems integration. 
- The involvement of private organizations in the transportation sphere provides further opportunities for coordination and integration. 


\section{CHAPTER 2. CASE STUDIES}

This chapter discusses several case studies regarding on-going large-scale transportation integration efforts in the United States. In order to identify those efforts we conducted the following activities: (a) we established a database of the most recent long range transportation plans for State Departments of Transportation and major metropolitan planning organizations; (b) we performed a keyword search on the selected planning documents looking for select terms related to our research, such as: integration, intermodal, multimodal, coordination, collaboration, sustainability, connectivity and information technology; and (c) we examined trends in keyword results and carefully examined those plans in the top tier (measured by the number of keywords that appeared in the document in meaningful context) for key examples of transportation integration activity.

In order to identify relevant information regarding integrated corridor management systems we: (a) researched integrated corridor management systems identified by the USDOT's Research and Innovative Technology Administration; (b) focused primarily on the US-75 Corridor in Dallas that has been completed; (c) briefly investigated the possibility of applying the integrated corridor management systems concept on NE Illinois roadways/corridors with a particular focus on auto/transit interaction.

The chapter is organized as follows. Sections 1 and 2 present, respectively, Michigan's and Florida's Departments of Transportation experience toward integration. Sections 3 and 4 discuss relevant integration experiences, respectively, in the San Diego and Dallas metropolitan areas. Section 5 focuses on integration policies in Illinois followed by three examples of integration projects in Illinois in Section 6.

\section{Michigan}

Michigan's Department of Transportation began working towards a statewide integrated transportation system with the publication of the 2007 Integration Technical Report, which serves as the starting point upon which current efforts rely. The objective of the report was to identify "how the integrated transportation system can best connect people and businesses with economic activities in Michigan." Developing a statewide integrated system is without question a difficult task, the 2007 report admits this. The document works to overcome these challenges by weaving connections to other planning documents and technical reports that provide opportunities for integration and coordination. These connections must be drawn between system components, system users, activities supported by the system, and the goals and objectives of system performance. 
An update to the 2007 Integration Technical Report was authored in 2012 to accompany an update to Michigan's State Long Range Transportation Plan. Building on the foundation laid by the 2007 Report, this document discusses the motivations for pursuing an integrated transportation system while also setting goals for the state to achieve through the implementation of the 2035 Michigan Integrated Transportation Plan. The driving forces behind Michigan's continued push towards an integrated transportation system include economic benefits and efficiencies and increases in livability and sustainability.

Key elements of the documents include the following:

2007 Integration Technical Report

(http://www.michigan.gov/documents/mdot/MDOT SLRP TR Integration20061116 19 8572 7.pdf - accessed 2/4/16)

- "The chief objective of this Integration Technical Report is to identify how the integrated transportation system can best connect people and businesses with economic activities in Michigan."

- The Integration Technical Report uses these insights from the other technical reports to build a statewide, multi-modal approach for planning an integrated transportation system supporting Michigan's economy.

- Planning for an integrated system requires defining concepts for relationships between:

o System components;

o System users;

o Activities supported by the system; and

o The goals and objectives of system performance.

o The report closes with a set of decision principles. These decision principles are offered to guide statewide planning and decision-making. The decision principles emphasize the importance of providing an integrated transportation system to connect people, businesses, and activities."

$\underline{2012 \text { Intermodal Integration White Paper }}$ (http://www.michigan.gov/documents/mdot/MDOT NewPolicylntegrationWhitePaperFin al 397570 7.pdf - accessed 2/4/16)

- Motivations for pursuing an integrated transportation system include:

o Economic benefits and efficiencies

o Emphasis on livability and sustainability

o Gubernatorial priority

- Integration is key to reaching the goals set forward by the 2035 MITP: 
o Stewardship

o System Improvement

- Efficient and effective operations

o Safety and Security

- Michigan Rail Plan - sought to improve freight and passenger rail transportation and addresses all goals of the MITP.

o Includes Michigan's participation in Accelerated Passenger Rail programs between Detroit and Chicago.

o Development of a rail/streetcar project on Woodward Avenue in Detroit.

- Improved connectivity between housing and employment

- Links major public transportation systems

o Coordinated Public Transit \& Human Services Transportation Plans

- More than 50 have been completed statewide

- Identify transportation needs of individuals with disabilities, older adults, and people with low incomes.

o Statewide Complete Streets legislation

- Enacted in 2010

- "Roadways planned, designed, and constructed to provide appropriate access to all legal users...whether by car, truck, transit, assistive device, foot, or bicycle."

- Requires sensitivity to local context.

o Transit Center Development

- Aim to facilitate transfers and coordination between statewide, regional, and local transit options.

o Transportation Alternatives for Commuters

- Online calculator tool that provides time and cost information to commuters in an aim to reduce SOV mode share.

o Carpool lots at Meijer Stores

o Intergovernmental Coordinating Council

Beginning with the 2007 Report, MDOT developed a set of decision principles that are available to guide statewide planning and decision-making. Not surprisingly, the principles aim to facilitate the creation of an integrated transportation system throughout the state. Emphasis is placed on building connections between people, businesses, and activities.

Michigan's 2012 White Paper report builds on the principles set forth by the 2007 Report by describing a number of different plans and programs that aid in the development of an integrated transportation system in the state. The first example highlighted in the White Paper is the Michigan Rail Plan, which aims to improve freight 
and passenger rail transportation while addressing the goals of the 2035 Michigan Transportation Plan. Projects of note contained within the plan included Michigan's participation in the Accelerated Passenger Rail program between Detroit and Chicago and the development of a rail/streetcar project on Woodward Avenue in Detroit that would improve connectivity between housing and employment and link major public transportation systems.

The other major initiative of note is the state's push towards developing Coordinated Public Transit and Human Services Transportation Plans. To this point, over 50 of these plans have been completed across the state by various levels of local government. These documents assess and identify transportation needs of individuals with disabilities, older adults, and people with low incomes. Improvements that benefit these groups provide improvements in the system for all users. One of these plans is reviewed in the following section.

The State of Michigan has engaged in a number of different activities that have helped move the state towards an integrated transportation system. These include a statewide complete streets program (enacted in 2010), the development of transit centers throughout the state that link national, regional, and local transit services, the Transportation Alternatives for Commuters program, partnerships with retailers in developing park and ride lots, and the establishment of an intergovernmental coordinating council.

\subsection{What are the Apparent Results In Michigan?}

The 2012 Intermodal Integration White Paper calls for the development of Coordinated Public Transit/Human Service Transportation Plans to aid in the state's transition towards an integrated transportation system. These plans are to identify the transportation needs of individuals with disabilities, the elderly, and those with low incomes. The Genesee County (Flint) plan relied on input from public, private, nonprofit, and human service representatives to assess the current state of transportation in the county and make recommendations for future changes. Stitching together a series of plans like the one produced by Genesee County would allow MDOT to develop the statewide integrated system that they described as early as 2007 .

Michigan's Transportation Alternatives for Commuters web page (http://www.michigan.gov/micommute/0,4623,7-214-53729---,00.html - accessed $2 / 4 / 16$ ) serves as an informational tool to assist residents in making cost-effective decisions for their trip to work. The tool features a cost-to-commute calculator (http://mdotcf.state.mi.us/public/rideshare/drivingcost.cfm - accessed 2/4/16). Presented 
alongside this information are links to information on rideshare, public transportation, bicycling, and walking as potential modes for commuting. In addition, Genesee County's plan (http://www.gc4me.com/Coordinated technical report 2040.pdf accessed 2/4/16):

- Was developed to identify the transportation needs of individuals with disabilities, elderly individuals, and individuals with low incomes.

- Was developed with assistance from public, private, non-profit, and human service transportation representatives.

- Assessed that additional services were needed for parents with young children, for the developmentally challenged, improvements in bus stops, and expanded transit services and hours.

- Assessed that these issues could be overcome by maintaining or increasing funding for services, facilitating coordination between organizations and businesses, addressing safety and security needs, and incorporating technology.

- Documented the most important strategy as voted on by stakeholders was maintaining and increasing funding for services.

\section{Florida}

In 2003, the Florida Department of Transportation created the Florida Strategic Intermodal System Plan (SIS) to aid in the establishment of an integrated system of transportation facilities and improve the state's economic competitiveness. The SIS focuses on critical transportation facilities and corridors that are the primary means of moving people and goods through its vital economic regions and into other states. These facilities encompass almost all of the state's commercial freight traffic and account for 89 percent of all interregional rail and bus passengers. The SIS was initially developed as a response to several statewide trends that continue to shape the state's economy and transportation system including meeting the growing demand of moving people and freight, linking Florida's economic regions, enhancing the state's economic competitiveness, balancing future growth with environmental stewardship, and making strategic choices with limited resources.

The SIS seeks to address a number of challenges that face both Florida's transportation system and the state as a whole. First, Florida's plans for the SIS meet growing demands for moving both people and freight throughout the state and the region. Improving connections and facilitating movement provides the opportunity to better link Florida's unique economic regions. Creating better connections and more efficient travel between these regions has the potential to enhance the State's economic competitiveness. The SIS addresses the fact that improvements in the State's 
transportation system will need to be made while considering the effects that improvements would have on the greater environment. As such, the plan seeks to balance future growth with environmental stewardship and to make strategic choices given limited overall resources. Within this framework the SIS strives to foster an integrated transportation system within the State of Florida.

Key elements of the SIS (http://floridatransportationplan.com/sis.html - accessed 2/4/16) include the following:

- Established in 2003, the SIS aims to enhance Florida's economic competitiveness by focusing resources on transportation facilities deemed to be critical to statewide and interregional travel.

o Selected corridors account for 89 percent of all interregional rail and bus passengers

- Challenges addressed through the SIS:

o Meeting a growing demand for moving people and freight

o Link Florida's economic regions

o Enhance economic competitiveness

o Balance future growth with environmental stewardship

o Make strategic choices given limited resources.

The first steps towards creating Florida's Strategic Intermodal System began in 2000, when the 2020 Florida Transportation Plan called for its development to address issues within the State's transportation system. By 2003, the SIS had been established after being molded by a 41-member steering committee that recommended policies and criteria for selecting the portions of Florida's transportation system that would become part of the SIS. The founding legislation behind the SIS designated the facilities that would initially make up the system, and included the findings presented by the steering committee that had put together a set of initial recommendations. After a year, legislation was passed that provided the framework for facilitating future improvements to the system, calling it the state's "highest priority for transportation."

Since 2005, FDOT has worked on implementing and revising the SIS plan in a number of different ways. These have included growth management, investments in military facilities, capacity improvements, public-private partnerships, and aviation planning. More specifically, in chronological order:

- 2000 - The 2020 Florida Transportation Plan, developed by FDOT with input from more than 30 statewide partners, called for development of the SIS. 
- 2002 - A 41 member Steering Committee recommended policies and criteria for designating which facilities should be part of the SIS.

- 2003 - Legislation established the SIS and authorized the designation of the initial facilities and services included in the system, incorporating the criteria and thresholds developed by the 41 member SIS Steering Committee by reference to its December 2002 final report.

- 2004 - Legislation provided the framework for funding future SIS improvements. This legislation identified the SIS as the state's highest priority for transportation capacity, identified initial funding sources, and made all SIS facilities eligible for state funding, regardless of ownership.

- 2005 - FDOT adopted the first SIS Strategic Plan, as required by state law. The plan built on the initial recommendations from the Steering Committee and extensive public and partner input.

- 2005 - Legislation authorized additional funding for SIS projects supporting growth management goals and directed FDOT to evaluate the connectivity between the SIS and military facilities and the impact of SIS investments on military facilities.

- 2006 - FDOT adopted the first SIS Multimodal Unfunded Needs Plan, identifying major capacity improvement needs through 2030.

- 2007 - Legislation clarified SIS designation criteria and update processes, expanded the potential role of public-private partnerships in advancing SIS projects, and added a new category of criteria for general aviation airports serving as relievers to SIS airports.7

- 2008 - FDOT adopted the first SIS Designation and Data Review report. This report documented all designation changes since the SIS Strategic Plan was adopted and identified designation related issues for the update process.

\subsection{What are the Apparent Results in Florida?}

The anticipated results of implementing the SIS plan are many and diverse. First and foremost, the plan seeks to improve interregional connectivity by improving and implementing multimodal corridors within the SIS. The system's overall level of integration can be improved through a number of different avenues. The first of these is efficiency. The SIS seeks to improve efficiency in the corridor by identifying bottlenecks and developing creative solutions to overcome them through both transportation and land use lenses. Another way in which the SIS aims to develop a more robust transportation system involves developing a series of choices (including modes, providers, etc.) that offer travelers options for completing trips. In order to facilitate these choices, updates to Florida's transportation system must include improved intermodal connectivity between different modes and services throughout the state. Making these 
improvements will strengthen the state's economy through improved coordination and travel, reduce the state's impact on the natural environment by making trips more efficient in terms of time and fuel consumption, and better serve residents in terms of emergency management through coordinated planning and access to strategic facilities throughout the state. In summary, the plan seeks to improve:

- Interregional connectivity - Develop or update multimodal corridor plans for key interregional travel corridors on the SIS.

- Efficiency - Continue to identify and evaluate bottlenecks on the SIS and develop strategies to reduce delay and improve reliability. Implement strategies for enhancing coordination with land use and development decisions to ensure SIS capacity is preserved for its intended purpose.

- Choices - Implement SIS designation policy changes to add selected urban fixed guideway transit corridors and to plan for future additions of integrated logistics centers and commercial spaceports. Continue to coordinate with modal partners to provide more alternatives for moving people and freight on the SIS, consistent with the statewide modal plans for aviation, space, seaports, waterways, rail, and transit.

- Intermodal connectivity - Reevaluate SIS connector designations and investment needs to ensure safe and efficient transfers between modes at all SIS hubs. Work with partners to designate 'hub-to-hub' transit and freight connectors where appropriate.

- Economic competitiveness - Strengthen partnerships with Enterprise Florida and regional and local economic development organizations to coordinate SIS investments with statewide and regional economic development strategies and to obtain continuing input on market conditions and strategic investment opportunities. Continue coordination with seaports, airports, and other partners to position Florida for anticipated growth in international trade. Continue proactive planning for Emerging SIS facilities.

- Energy, air quality, and climate - Work with partners including through updates to the FTP to consider how transportation decisions can help meet statewide goals for reducing energy consumption, air pollution, and greenhouse gas emissions. Evaluate the potential risks to transportation facilities due to sea level rise and other anticipated impacts of global climate change.

- Emergency management - Complete the designation of access facilities linking the SIS to the state's strategic military installations, and begin working with base commanders and other military partners to identify access needs and the roles of the state, federal, and local governments in meeting these 
needs. Strengthen coordination with emergency management agencies to ensure the SIS can support emergency evacuation and response needs.

\section{San Diego}

The San Diego Association of Governments (SANDAG) serves as the Metropolitan Planning Organization (MPO) for the San Diego Metropolitan Area responsible for multipurpose regional decision-making across 18 cities and San Diego County, having a population of 3.2 million. On January 1st, 2003, following passage of State Law SB 1703, SANDAG responsibilities were expanded, consolidating within SANDAG regional long range transit planning, project development, programming and construction that had previously resided independently within each of the region's transit operating agencies. Day-to-day transit operating responsibility along with regulatory authority over taxi services remains with the San Diego Metropolitan Transit System (MTS) and its operating subsidiaries, while the North County Transit District (NCTD) independently operates a family of transit services in north San Diego County.

The organizational and institutional changes that have occurred make SANDAG an exemplary case study of contemporary efforts towards creating an integrated regional transportation system that considers all modes along with policy and project links to non-transportation issues including land use and management of the natural environment. These broader efforts towards integration have resulted in an overall improvement in the transportation system's performance on all levels and merit further study by peer regions looking to better integrate their own transportation networks and development policy goals.

The reorganization of transportation-related agencies in the San Diego metropolitan region was officially approved through the passage of California SB 1703 on January 1st, 2003. This bill authorized SANDAG to take over certain responsibilities and functions of the MTS and NCTD. Responsibilities that were selected included longrange planning, project development, programming, and construction. Along with reorganization, the bill called for SANDAG to redefine institutional roles, and responsibilities in an aim to separate operational activities from regional and strategic activities. In response to this charge, SANDAG facilitated the development of a twenty member regional governing board made up of representatives selected from across the county. Four primary committees were also implemented (executive, transportation, regional planning, and borders policy) to oversee the agency's activities. Reorganizing and refining roles within SANDAG combined with an expanded regional role have allowed for the development of a more integrated transportation system in the San Diego region. 


\subsection{What are the Apparent Results in San Diego?}

The reorganization and redefinition of SANDAG's role in the San Diego region has reinforced a link between transportation, transit planning, and broader regional goals. In its authorization of SANDAG's organizational changes, SB 1703 stated that there was a demonstrable need in the region for an agency with sufficient authority in both land use and transportation matters to construct wholescale, comprehensive plans. These plans would then, in time, allow for the creation of an integrated transportation system in the region. Institutional efficiencies drawn out from the changes in SANDAG stem from a renewed focus on collaborative planning with other regional stakeholders. SB 1703 calls for SANDAG to leverage the recommendations and opinions of member agencies, local governments, state and federal agencies, educational institutions, research institutions, civic groups, and individuals within communities. By combining input from these stakeholders, SANDAG will be able to help create an integrated transportation system that serves all users. These collaborative directives have led to a more streamlined and effective consultation process. SANDAG acts as a repository of sorts of completed plans and mapping exercises that can be accessed by local agencies and used to inform their decisions, helping plans throughout the region to work towards the same standards of an integrated system. SANDAG's Regional Comprehensive Plan (RCP, 2004) calls for a focus on improving connections between land use and transportation systems, using those relationships to guide public investment throughout the region.

Further, the Plan states that collaboration between local and regional stakeholders will be essential in successfully carrying out these objectives. The RCP covers a vast array of topics, helping to influence and achieve integration throughout the region on issues related to transportation, congestion, sprawl, environment, and economy. Public investment throughout the region is fueled by TransNet, the region's dedicated sales tax that funds infrastructure investment. Money from this program is not only used to develop new infrastructure, but also to aid in mitigating environmental damages that have been caused by previous projects. SANDAG has been instrumental in its use of emerging transportation technologies. It is currently participating in RITA's Integrated Corridor Management program through a pilot project on the Interstate 5 corridor. SANDAG's 2050 Regional Transportation Plan calls for further use of Transportation Systems Management and Transportation Demand Management technologies to leverage capacity that already exists within the system.

\section{Dallas}

The US-75 corridor in Dallas is currently the most prominent Integrated Corridor Management (ICM) pilot project in the country. US-75 is the major north-south route 
through the Dallas-Fort Worth area, and is one of the most congested highways in the country. The corridor also consists of frontage roads along the entire length of the study corridor, 167 miles of arterials, a bus network and a light rail both operated by Dallas Area Rapid Transit (DART).

The ICM project's efforts for the US-75 corridor involved the cooperation of multiple agencies across municipal jurisdictions. To implement the ICMS, extensive modeling of the corridor was performed at the micro, meso, and macro levels, examining congestion resulting from a traffic incidents, weather, time of day, and special events. From these models the Decision Support System (DSS) was implemented. This system allows for efficient redirection of traffic flow after an incident is identified. When an incident is reported to the system, the DSS is automatically altered and evaluates situation based on location and severity of incident, time of day, availability of alternate routes, travel times and capacity on alternative routes, transit and park-and-ride lot capacities. The DSS recommends a response plan from a list of plans. Each operating agency can choose whether to implement the recommended plan. If the plan is implemented, dynamic messaging signs (DMS), 511 website, and media outlets inform commuters. The DSS continually evaluates the situation and continues to make recommendations as the situation changes.

The other broad ICM program implemented in the US-75 corridor is the Targeted Event Accelerated Response System (TEARS). This initiates optimized traffic signal timing in the corridor during incident conditions, including crashes, special events, and planned construction. The Dallas ICM project was able to study this concept because they had a mesoscopic traffic model of the corridor, data on signal optimization, and almost all traffic signals in the US-75 corridor were connected to their operating agency's Traffic Management Center.

The study focused on crashes, which were classified into five possible categories, one with minor impact, a major impact with diversion to frontage roads, a major impact with diversion to parallel arterials, and, if warranted and feasible, a major impact with diversion and mode shift to transit. The study divided the corridor into segments between off-ramps, and identified 426 response plans, covering all crash scenarios with AM, midday, \& PM versions. These scenarios were clustered together and studied to determine which situations would be candidates for detailed signal timing plan development. Twenty one clusters of incidents were chosen \& entered into the traffic model. Outputs from that model were entered into the signal timing model to develop TEARS plans. 
For the vast majority of scenarios, the model recommended monitoring the crash but not implementing any multi-agency plan. Twenty-five scenarios recommended DMS message changes but no signal timing changes. Twenty-seven scenarios recommended between three and forty-nine individual signal timing changes. The study was able to examine only a relatively small proportion of potential scenarios. The report did not indicate whether the signal timing changes would be implemented when the DSS response plan recommends commuters divert their route.

\subsection{What are the Apparent Results in Dallas?}

Results of the pilot program are not yet available. However, lessons learned have been presented. To successfully implement integration strategies across agencies and jurisdictions, the Dallas program stressed the importance of identifying all stakeholders and explicitly stating which agencies hold responsibility and authority from the beginning of the program.

\section{Illinois Integration Policies}

Legislation regarding transportation integration in Illinois exists, but is rather brief. One major piece of legislation on the topic is the Regional Transit Coordination Plan (RTCP) of 1999. The RTCP is derived from the 1983 RTA Act Amendment, which decentralized the day-to-day transit responsibilities to the three service boards - CTA, Metra, and Pace - while simultaneously calling for improved overall planning and coordination to achieve an integrated and efficient regional transit system (42).

In 1999, the 91st Illinois General Assembly authored House Resolution 234 to satisfy the RTA Act's requirement of creating a coordinated regional public transportation system. This resolution provided up to $\$ 400,000$ to the RTA to be used towards the development of a regional transit plan (later deemed the RTCP) which funded consultations with the public through focus groups/public meetings, and also mandated the RTA's investigation into several coordination opportunities including:

- Metra and CTA interchanges where rail lines are in close proximity,

- Pace services at Metra and CTA stations for reaching employer destinations,

- Station signs, maps and schedules to inform riders of transfer connection options, and

- Universal fare cards to facilitate transfers (44).

The RTCP was constructed and finalized between 1999 and 2006. It consisted of 4 major studies related to differing aspects of coordination in the region: 
- The Physical Coordination Study focused on the ease of transferring between various modes operated by CTA, Metra, and Pace. Existing and potential transfer locations were studied to look for connection points in need of improvement.

- The Information Coordination Study focused on the utilization of signage, maps, and schedules to improve the transit rider experience. Several improvements were developed through this study including advances in wayfinding signs at interagency transfer locations, system-wide maps, and enhancements of existing information sources and centers.

- The Service Coordination Study aimed to investigate ways to better connect regional travel markets in a cost-effective manner. Several ways to improve regional mobility were discussed including the use of buses to connect activity centers and aid in servicing reverse-commute and suburb-to-suburb travel markets.

- The last study administered was the Fare Coordination Study. The primary goal of this study was to identify opportunities to make it easier for customers to pay to travel on different parts of the RTA system. The study delves deeply into the potential use of a universal fare payment system and the costs and benefits associated with a variety of implementation options (43).

The RTCP was an attempt to address and correct transportation integration and coordination issues in the Chicago region. Despite the fact that the document itself accomplished what it was intended to do, there appeared to be little follow-through in subsequent years.

One aspect of the RTCP that continued was an investigation of utilizing universal transit fare cards. In 2011, the Illinois General Assembly passed HB3597, a public act, mandating the development of a universal transit fare card system to be used among the transit agencies in Northeastern Illinois. This act charged the RTA with developing a policy to reduce the cost of transfers for all public transportation services provided by the Service Boards, and mandates the implementation of such a service by January 1 , 2015 (16). Currently the CTA and Pace have agreed to switch to a new fare payment system (Ventra) in the fall of 2013. Metra made Ventra available to customers in the fall of 2015.

Again in 2011, the Illinois General Assembly approved another item to improve the transit system in Northeast Illinois. HJR0024 required both the State House and Senate transportation committees to hold a joint hearing and collect testimonies from the RTA and the three service boards regarding how to move towards a more modern and better transit system for the region. It was also required that the committees create a report 
and submit their final findings to the General Assembly (17). That report was issued in July of 2011, and the RTA responded with a report titled Transit Priority Initiatives.

The RTA and the service boards that serve the region have faced significant financial challenges in recent years. Infrastructure across the system continues to increase in age, and due to the economic recession, funding for transit improvements has been limited. The Illinois General Assembly's report asked the RTA and the service boards to improve coordination while also cultivating a strategic capital approach that focuses on reducing operating expenditures, improving efficiency and cost savings, identifying opportunities to maximize the use of the transit system, bettering the overall customer experience, and creating a unified marketing, outreach, and government affair approach (54). In response to this report, the RTA launched a collaborative effort that focused on several initiatives to advance the regional transit system including:

- Strategic Capital Investment - Reduce operating cost by identifying capital projects that could result in reductions in operating expenditures.

- Economies of Scale - Identify areas such as fuel, insurance, and utility purchases where coordinated purchasing efforts with the service boards and other government agencies could achieve cost savings and improve efficiency.

- Maximize Use of System - Maximize the use of the existing system by better tapping into travel markets that have potential to use transit in places where the system is not running at capacity. Through improved coordination in marketing and service delivery, the service boards are exploring opportunities to better penetrate the reverse commute market, as well as weekend and evening travel markets.

- Enhanced Customer Experience - Focus on targeted capital and technology related projects, inter-agency and way-finding signage, e-signage, service improvements (such as Wi-Fi), service information (such as expanded "bus tracker" type information) and fare payment coordination all in an effort to serve RTA customers.

- Coordinated Government Affairs, Marketing, Outreach - Coordinate with the service boards on customer information while increasing the coordination and leveraging of partners and other stakeholders.

- Customer Care Coordination - Utilize a comprehensive approach to address opportunities in improving customer information (54).

The RTA has formed several interagency teams to assist and implement many of the initiatives created from the General assembly's recommendations. All these initiatives try to address three of the RTA's goals including increases in ridership, decreases in 
operating costs, and improvements in transit service on the whole (54). The RTA's 2012 strategic plan also highlights a majority of these initiatives.

\section{Examples of Integration in Illinois}

Similarly to overall policy related to integration in Illinois, major examples of these policies in practice have been limited in the region. Of the few examples that do exist, only two stand out as proper examples of integration. The Bus-on-Shoulders Demonstration Project and Parking Management Guidance System Project showed extensive collaboration and coordination between agencies and stakeholders. Both of the projects also represent a variety of modal interactions including those between rail, bus, automobiles, park and rides, bicycles, and pedestrians. The following sections offer case studies and detailed information of both projects.

\subsection{Bus-on-Shoulders Demonstration Project on I-55}

An expansion of transit facilities in and around Chicago seemed highly unlikely following the recent recession and lack of traditional funding sources. Many of the available funds were used for maintaining the existing transit system, leading to an uncertain future and forcing the regional transit system to do more with less. In 2010, the Chicago Metropolitan Agency for Planning (CMAP) introduced the regional long range plan GO TO 2040 which identifies several cost efficient goals and strategies to improve the existing transit system (10). It was one of these strategies that eventually led to the implementation of the bus-on-shoulders (BOS) demonstration project.

Acquiring the right-of-way is one of the largest costs of any transit capital project. Finding a way to bypass this step makes projects much more affordable. The Chicago region presents an interesting situation because it has a fairly extensive regional expressway and tollway network, of which very little is used for transit purposes. This underutilization opens the door for potential shared use strategies like bus-on-shoulders (34). The Illinois General Assembly was intrigued by this very possibility asked the RTA, IDOT, and Pace Suburban bus to collaborate and establish a BOS demonstration project on I-55 through an amendment to the RTA Act in 2008. This demonstration project was considered a low cost, quick to implement venture that could serve traditional commuters in areas with a lack of commuter rail services (31). One obstacle encountered through the process was that the Illinois Vehicle Code did not permit buses to operate on highway shoulders. In August of 2011, the Illinois General Assembly amended the vehicle code, permitting buses to legally use the shoulder and the BOS demonstration project was officially underway (15). 
The concept of BOS is neither new nor exclusive to the state of Illinois. BOS has been implemented in cities all across the country in years prior. Through extensive review of the literature and those systems, the Chicago region has created a unique blueprint to implement its own BOS project $(4,23,51)$. After much consideration, the I-55 (Stevenson Expressway) between Kedzie Avenue and I-355 was selected as the best place to showcase the BOS demonstration project for several reasons. The corridor lacks convenient access to commuter rail services, which results in many travelers choosing to drive into Chicago's downtown. The lack of viable transit options in the corridor therefore creates severe congestion during peak travel periods. Pace services already existed as commuter routes along I-55, but had very unreliable travel times due to high congestion levels. All of these factors played a role in leading to the selection of this corridor; however, one of the most important factors leading to the selection of I-55 was that much of the corridor had a continuous shoulder of 12 feet or greater. This would allow for the BOS demonstration to be implemented with very limited construction and at a low cost (10).

The aforementioned Pace transit service existed on the I-55 corridor since 1987, and had expanded service sequentially in 1990 and 2009. Pace operated two weekday peak period express commuter services from the western/southwestern suburbs to downtown Chicago. Both routes, 855 and 755, originate in Plainfield and travel mainly via I-55, but periodically venture away from the interstate to pick up passengers at designated parkand-ride locations in Plainfield, Bolingbrook, and Burr Ridge. The routes then express toward downtown Chicago with the 855 route terminating in the loop, and the 755 route serving the Illinois Medical District and then terminating in the West Loop at Union Station (13). The express routes operated 8 buses a day during peak periods and directions, and had an average daily ridership of about 330 passengers. Due to heavy levels of congestion, both of the routes often experienced a high variability of travel times, paving the way for the BOS demonstration project (13).

The purpose of the BOS demonstration project was to determine whether transit use of the highway shoulder can improve travel times and customer perception, while maintaining the normal operating function of a highway shoulder. This form of transit has a plethora of potential benefits and has the potential to improve service along a corridor that lacks adequate access to commuter rail service. The perceived benefits of BOS service include an increased ability to move people along the highway corridor, improved running time and reliability, improved customer experience and convenience, new transit ridership, and increased transit capacity (10).

The BOS demonstration project was accomplished through a series of intricate planning steps. In 2009, the RTA and several consultants conducted a peer review and a 
feasibility study for the project. The peer review investigated 6 metropolitan areas that had previously implemented BOS, and discussed detailed information including legislation involved, specifications, the implementation process, and in many cases the results of implementation (4). Aspects of this review were then used to develop the feasibility study, which identified and evaluated a series of reasonable alternatives that could be implemented in Chicago. It focused on comparisons between inside and outside shoulder transit service, design criteria and operating assumptions, details of inside shoulder alternatives, and various evaluations for the corridor (20). In order for the BOS project to be a success, a substantial amount of collaboration between stakeholders needed to occur. The RTA formed a BOS study group made up of representatives from federal, state, and local agencies that all had a vested interest in the I-55 corridor (34). The primary purpose of the study group was to provide policy and technical guidance for the demonstration, to guarantee collaboration and participatory planning, and to ensure that all stakeholder issues and concerns are addressed (34).

The BOS demonstration project was sponsored by three major agencies in the realm of Illinois transportation: the RTA, Pace Suburban Bus, and IDOT. The Federal Highway Administration and Illinois State Police were also involved, with the police being responsible for traffic enforcement during the duration of the demonstration (53). After all the agencies were on board, the RTA conducted a phase 1 study to plan and develop the BOS project for the Chicago region. One major takeaway from the phase 1 study was that although most of I-55's shoulders were 12 feet or greater, they were not all able to structurally support bus travel. To solve this issue, IDOT and the RTA collaborated to get shoulder pavement improvements onto the next construction capital program (53).

Another major collaboration effort between the agencies was for the development of a media and public awareness campaign. In order for the BOS demonstration to be successful, the agencies had to promote the service to attract riders and also make users of I-55 aware of this new transit option for safety reasons. One of the biggest concerns shared by stakeholders was whether or not the shoulder could maintain a normal and safe function for all other vehicles, as well as ensure that users would not follow the bus on the shoulder. These issues were addressed through the agencies' massive media campaign, which involved public meetings, press releases, informational videos, and social media coverage (7).

The BOS demonstration project started in the fall of 2011 and is made up of three discontinuous segments on the I-55 corridor (20). The segments add up to approximately 16 miles of travel lanes in both northbound and southbound directions and comprised of the following: 
- Kedzie Ave to BRC railroad (1 mile)

- Cicero Ave to I-294 interchange (8.7 miles)

- County Line Rd to I-355 interchange (6 miles)

The BOS lanes are located on the left side (inside shoulder) of the roadway and can only be used if traffic is moving at a speed of less than $35 \mathrm{mph}$. The use of the shoulder is completely up to the discretion of the bus operator. When driving on the shoulder, buses are prohibited from traveling faster than $35 \mathrm{mph}$ and are limited to traveling at 15 mph faster than the current flow of traffic. Buses must yield to all other vehicles that enter the shoulder, and have to reenter the main travel lanes to avoid all obstructions including those from weather, accidents, emergency vehicles, etc. The buses are only allowed to use the shoulder when they are operating a route, and are restricted access if they are deadheading (10).

For the duration of the demonstration, IDOT was responsible for maintaining the shoulder and keeping it safe for bus operations by clearing debris, large obstructions, and snow as a part of regular highway maintenance operations. After major snowfalls, the shoulder may be of limited use for buses under IDOT's current highway maintenance program; however, IDOT is working on a new maintenance program that will clear the shoulders in a more efficient and regular manner (10).

In order for the project to be a success, prompt and efficient streams of communication are needed between the Pace drivers, Pace operations center, and IDOT's operation center. Pace has to communicate and report to IDOT on any obstructions that have occurred in the shoulder including maintenance, debris/hazards, breakdowns, unauthorized cars using the shoulder, and incidents. Contacts between the agencies have been predetermined so there is a streamlined process of reporting. IDOT also has included Pace on its short list of alerts from its Illinois Traffic Alert System, so they will be notified of roadway issues as soon as possible (10). An incident management plan was also developed that provides guidelines for evacuating an operating transit vehicle. The plan follows standard procedures of peer systems, and can be summarized into two easy steps. In case of an emergency the bus should try to get over to the right shoulder and contact the dispatch center. If this is not possible the bus should stay as far left in the left shoulder that it can be (10).

The BOS demonstration project has been extremely successful to date. In August, 2014 legislation was passed to make the program permanent. Since the program began, ridership and on-time performance have drastically increased, and service has been expanded. Since shoulder operations began in mid-November, 2011, ridership has grown significantly on both routes. In March, 2011, Route 755 carried an average of 40 
passengers per day. As of March, 2013, that number leapt to 137 passengers per day, an increase of over $240 \%$. Route 855 jumped from averaging 281 passengers per day in March, 2011, to 451 per day in March, 2013- an increase of over $61 \%$. On-time performance for the routes improved from roughly $68 \%$ in 2011 to a range between 90 $93 \%$ as of late $2012(31)$.

The improved on-time performance has certainly attracted more riders, and due to the demonstration's success, BOS activity is being expanded in the region. Indeed in May 2014, PACE the expanded number of rush hour bus trips for Route 755 \& Route 855 , new midday and late evening Route $755 \& 855$ trip, eliminated reverse-commute trips for 755. The program was expanded further in August 2014 to split Route 855 into Routes 850,851 , and 855.

\subsection{Parking Management Guidance System - A Chicago Case}

The Parking Management Guidance System (PMGS) was a pilot project undertaken by the RTA with the assistance of Wilbur Smith and Associates in the late 1990s. The project was one of four corridors selected by the United States Department of Transportation as part of its Intelligent Transportation System Initiative. The focus of this initiative was to aid in the creation of a more efficient system of use for existing Metra commuter parking lots by informing motorists of facility locations and real-time transit parking availability (37). A series of three reports were produced as a result of the study (http://www.rtams.org/rtams/planningStudy.jsp?id=30 - accessed 2/4/16), outlining the way that Park and Ride facilities could be integrated through the Gary-ChicagoMilwaukee Multimodal Traveler Information System. The study includes an inventory of existing parking facilities, the changes that would need to be implemented to intertwine existing facilities into an ICM style corridor, how users would interact with the system, and some ways that the system would function once it was to be put in place.

The study reports above identified three classes of park and ride facilities within the Northeastern Illinois region. These include scattered site parking, large surface or garage parking, and limited parking in urban areas. Scattered site parking consists of moderate to small sized parking lots that can be found throughout both urban and suburban parts of the region. Large surface or garage parking facilities appear as they are described, and are typically owned by one of the major transit agencies. These facilities are commonly located in surrounding suburban areas. The third type of facility listed within the report is the class of small facilities located in congested urban areas. These include street parking and small lots owned by cities or private developers. In the City of Chicago, lots that are a part of the newly implemented smart parking system 
(under the direction of Chicago Parking Meters, LLC) may serve as an interesting example of this type of facility given that they already use a "smart" interface (28).

These three general categories can be broken down more specifically in the Chicagoland region. There are four types of parking facilities for transit in the region including multimodal centers, Metra stations, CTA rapid transit stations, and Pace park and ride facilities. Multimodal centers include at least two modes of transit including CTA rapid transit, Metra commuter rail, and/or CTA and Pace buses. Examples of these facilities are generally located closer to downtown areas and include stations such as Jefferson Park, Harlem Avenue, and Davis Street (28). Metra stations are mostly located outside of the central area of Chicago and are often served by Pace buses. Some of these stations have large park and ride facilities and/or parking structures, while the majority is served by scattered surface lots (28). CTA rapid transit does not offer many park and ride facilities; however, those that are offered are located toward the edges of its network. The largest facility that is currently controlled by the CTA is the 1,600 space Cumberland Park and Ride on the Blue Line. In addition, CTA offers facilities along the Orange Line, at the Rosemont and Forest Park stations on the Blue Line, and at the Dempster Street station on the Yellow Line (28). Pace also offers a variety of park and ride facilities. Many of them connect its riders to Metra and CTA stations or employment centers via feeder or express routes. Unlike other facilities in the region, Pace park and ride facilities are generally smaller in scale and do not charge a parking fee. The Schaumburg-Woodfield area in the northwest suburbs contains one of Pace's largest bus passenger facilities (28).

Parking management systems traditionally did not address traveler information needs and were developed to bolster revenue collection systems (47). In order to provide realtime parking availability, the previous reports on PMGS address how parking status can be monitored, as well as the current parking operations used by the RTA and the three service providers. There are three basic ways of monitoring the status of parking: total number of spaces, zone specific, and space specific. The total number of spaces method is considered to be the simplest and most common form of monitoring the status of parking availability of lots (47). As car enters or exits a parking facility, a sensor or some kind of access control is used to monitor the total count of vehicles in the facility. This simple overall count can be displayed to commuters via signs or on the internet.

Zone specific monitoring is similar to the method of monitoring a facility by focusing on the total number of spaces, except it refers to specific areas or levels within a lot or facility (47). This method often uses a guidance system or detailed signage to direct users quickly to the closest area with available parking. The last and most complex 
method is space-specific monitoring. This method uses an abundance of sensors, often in every parking spot, to direct the user to the closest available parking spot. Due to the large amount of equipment and technology needed to implement this system, it has not been practiced at a large scale in the region (47).

Currently very few commuter parking facilities monitor and communicate parking availability in the region. Gate access control is used at the Rosemont and Cumberland CTA park and ride stations, displaying a sign that reads "FULL" when the lot is at capacity, but it does not offer overall parking availability. Most Metra stations do not maintain any form of parking control because the majority of facilities are not owned and monitored by Metra. At these facilities, manual pay boxes or electronic pay boxes are used to collect parking fees, but the current systems do not offer the functionality needed to determine the amount of available parking without engaging in manual counts (28).

Another important aspect of guiding commuters to facilities and stations is the use of signage. Metra utilizes signage on arterial roadways leading up to their parking facilities, but this varies by community and there is not always adequate signage directing travelers to specific parking lots near the actual station. CTA has signage for their Blue Line Park and Ride facilities along corresponding expressways, but directional signage on the arterials is lacking (28). An overall lack of signage for large facilities and/or at scattered parking lots poses major problems for the traveler, forcing them to travel from lot to lot or search for on street-parking. The combination of these obstacles makes switching from one's automobile to transit less convenient (28).

The RTA, in conjunction with Wilbur Smith Associates conducted a survey in order to better understand the system's users and evaluate the PMGS's effectiveness. The survey was conducted at 11 facilities to represent a cross section of multimodal, Metra, and CTA facilities, and looked to measure the current parking needs of its users, as well as their thoughts on parking information and accuracy (28). The survey was interview based and was conducted during the morning peak at the designated stations. A total of 316 surveys were completed with a majority of the data coming from those of working age. The survey aimed to satisfy two research goals. The first was to see how parking availability affects mode choice, and the second was to see if additional and convenient forms of parking information would encourage more people to take transit. One of the major questions asked of participants was what would they do if their preferred lot was full: park further from the station, drive to another CTA or Metra station, ride a bus to another station, or drive to their destination. Of those interviewed, 58 percent said that they would park further away from the station. Eighteen percent said that they would drive to their destination. This 18 percent was of particular importance for the project 
team because it represented the loss of ridership associated with inadequate parking facilities (28). Another question asked as part of the survey referred to the signage at parking facilities. Of those interviewed, 62 percent stated that parking signage in and outside of lots could be improved, (52 percent for CTA and 74 percent for Metra) 85 percent agreed that some type of electronic parking availability sign would be beneficial, and 57 percent stated that information regarding parking availability located on the internet would be a useful tool (28). The 74 percent of Metra customers who wanted improved parking signage demonstrates a significant need for improvement at these facilities.

\subsection{I-90/Jane Addams Tollway Bus on Shoulder}

As part of the Move Illinois capital program, $\$ 240$ Million from Illinois Tollway has been allocated to fund transit improvements on I-90/Jane Addams Memorial Tollway. This will allow Pace to purchase new transit vehicles, construct new park \& ride facilities at Randall Road/I-90, II 25/I-90, and Barrington Road/I-90, and improve access at the Rosemont CTA Station. BOS will be introduced on I-90, and current road widening is being done with potential for bus-only lanes in the future. Expanded Pace routes on I-90 will begin running in 2016 .

\section{Summary}

The previous case studies showed that initiatives toward transportation integration in the United States are flourishing and provide evidence that transportation integration could be part of the solution in providing a more efficient and effective transportation system. Below are some of the highlights of these efforts:

- In Michigan, a number of different activities that have helped move the state towards an integrated transportation system include: a statewide complete streets program, the development of transit centers throughout the state that link national, regional, and local transit services, the Transportation Alternatives for Commuters program, partnerships with retailers in developing park and ride lots, and the establishment of an intergovernmental coordinating council.

- In Florida, the implementation of its Strategic Intermodal System plan is under way through growth management, investments in military facilities, capacity improvements, public-private partnerships, and aviation planning.

- In San Diego, its regional comprehensive plan is being implemented. The region funds infrastructure investment through a dedicated sales tax. The region is currently participating in RITA's Integrated Corridor Management program. 
- In Dallas, considerable developments in the implementation of Integrated Corridor Management system, have resulted in a Decision Support System and the Targeted Event Accelerated Response System. The Dallas initiative stressed the importance of identifying all stakeholders and explicitly stating which agencies hold responsibility and authority from the beginning of the integration program.

- In Illinois, the Bus-on-Shoulders Demonstration Project and the Parking Management Guidance System Project have shown extensive collaboration and coordination between agencies and stakeholders. Both of the projects represent a variety of modal interactions including those between rail, bus, automobiles, park and rides, bicycles, and pedestrians. Additional integration efforts are being planned on I-90/Jane Addams Memorial Tollway. 


\section{CHAPTER 3. INTERVIEWS WITH STAKEHOLDERS}

In Fall 2015, the research team conducted structured open-ended face-to-face interviews with a number of transportation officials in Chicago area agencies involved in the case studies in Chapter 2. The following agencies participated in the interviews: Regional Transportation Authority (RTA), Illinois State Toll Highway Authority (ISTHA), Pace, Cook County and DuPage County. Informed by findings from Chapters 1 and 2, we developed a list of questions as follows:

- In our research we have examined several concepts including transportation integration and mobility management. These are broad terms with a variety of definitions in use. How would you define the terms? Are they different and if so, and how do they interplay?

- Please discuss some strategies your agency is implementing or has implemented to improve mobility for the people of the region.

- How have you addressed integration of modes in your strategic plan?

o Have you operationalized your approach toward integration into short term and long-term strategies?

- How do you coordinate with other modal agencies to plan park-and-ride facilities, new transfer locations, or other facilities to help people change between travel modes?

- Through what formalized processes do you engage with other agencies?

o Which interagency boards or working groups do members of your organization participate in?

o Who in your organization sits on those boards?

o Please discuss some of the work that happens in those groups.

o How do you establish the expectations and responsibilities of all the stakeholders?

- What are some informal processes through which your agency works with other agencies? What has been accomplished as a result?

- How do you engage with other stakeholders in your planning or implementation processes?

o For example schools or large employers that generate many trips?

o Or people affected by noise from your infrastructure?

- What are some challenges you've faced in interacting with other agencies?

- What are some barriers to integration?

- Who are champions of integration? What are some best practices?

- Are there any means through which your agency shares data, such as traffic conditions, incidents on the road, or service disruptions, with other transportation agencies? 
o In the Dallas US-75 corridor, municipalities share data regarding road conditions on each stretch of the corridor for which they have jurisdiction. This allows their ICMS system to be more accurate and allows the users to be more informed of travel conditions. Is there anything similar that exists in the Northeast Illinois region?

o Could something like this benefit mobility here?

The interviews took place on separate days in the offices of each participating agency. This chapter summarizes the responses focusing on the highlights from each interview. We have also identified common themes from the interviews, which we discuss at the end of the chapter.

\section{Highlights from the Interview with the RTA}

RTA views transportation integration as a concept in both the physical realm and in terms of policy integration.

When asked for examples of integration, many of the most immediate examples cited in the interview were of physical spaces where travelers are able to change between modes. The first physical space mentioned at the beginning of the interview was of Union Station "having a bunch of different modes all through one space in a four to six block area”.

Policy integration efforts cited included a fare pricing model that RTA developed for the service boards. This tool allowed the service boards to predict how fare changes by one service board would affect ridership and revenue on the others. Another was RTA's interagency sign program, in which RTA puts directional and wayfinding signs in locations where transfers between different agencies' transit systems are possible.

Both formal and informal channels are utilized to help agencies work together in the region.

Project sponsors typically invite RTA to be on technical advisory committees for the projects or to review deliverables. CMAP has repeatedly led efforts that engaged RTA either on panels or by sending project deliverables for review and comment. More recently, the Tollway (ISTHA) has engaged the RTA on the Tri-State reconstruction project.

Personalities play a large role in the processes of interagency collaboration. For example, on one project (Illinois 53 North) they wanted Leanne Redden to sit on the committee because she has a municipal and tollway background, even though she is 
with the RTA now. Sometimes a specific person will bring a broader perspective based on their experiences.

The future of integration efforts ought to be focused on information sharing.

The topic of information sharing was reiterated numerous times throughout the interview. The RTA began utilizing data to create a trip planner 10 years ago, but is ready to get out of the trip-planning field because the private sector, namely Google, can do it better. Instead, the RTA's role should be one of collecting schedule data and real-time travel data for transit and providing it to the creators or trip-planning technology. The importance of the RTAMS database as a resource for other agencies and their consultants was mentioned as a case in point.

Another example cited is a demonstration project in the region from the early 2000 s where dynamic message signs displayed information about train travel time and parking lot availability. A future effort such as this incorporating smartphones rather than dynamic message boards can hold potential for integration.

The largest impediment to integration is a lack of funding. "It's tough because the pie is so small". Because there likely won't be enough funding for as many large infrastructure projects in the future as there were in the past, information provides the best opportunity to improve the travel experience for people in the region.

Conversely, lack of data-sharing is an impediment to integration. For example, Cubic collects ridership data through the Ventra system that neither the service boards nor the RTA has access to. This was cited as an example of turf issues among stakeholders.

\section{Highlights from the Interview with the ISTHA}

\section{Clear understanding of goals and vision is integral to integration.}

Agencies [in the region] are often willing to work together to compromise or discuss how their projects can work to benefit the goals of partner organizations. However, from the Tollway's perspective, when partner stakeholders are not precise in their goals or wishes, the Tollway thinks these negotiations are not as productive as they could otherwise could be.

"The other barrier is a lack of vision on some agencies' part. What do you really want to do? You should be thinking about what you want to be, and it's hard to pull it out of people." 
"The other challenge is making sure, from a planning perspective, that communities and councils of governments (COGs) talk about a plan, but when we're going to start a project we send out letters to give us their plans and their concerns. We got 13 responses out of 88 plans. You need to have the foresight to know what you want in a space at least. We're very much an integral part of these communities but they don't want to pay too much attention to us. It's always a challenge to get them to tell us what they want."

The I-90 corridor was repeatedly referenced as a satisfying example of planning integration among the stakeholders. This was partly attributed to the clear vision and demands from interested parties.

"I guess on I-90 it was very clearly a case where the partnering agencies knew what they wanted. They invested a lot of time studying the STARline and alternatives like bus rapid transit. So they actually had a pretty robust understanding of what they wanted to see happen.[...] I would say the vision was very much a partnership. It's unique. I would say it doesn't happen all too often that way. On I-294, you're right, people don't think about these things the same way the Tollway does. We're having a harder time getting transit to articulate what they want there."

\section{Project timing and resource allocation.}

One theme that has emerged from many studies of integration challenges is that of funding. That theme emerged in this interview, although from a different perspective than usual. The Tollway has relatively short planning and construction schedules compared to other agencies with whom they work. Although the Tollway does not feel that their agency is lacking in resources, they find that other agencies cannot allocate resources on the same schedule. Because other agencies can't work on the same schedule due to fiscal and staffing constraints, opportunities for integration can get overlooked.

"Our resources are not an issue, but we're forcing others to reallocate their resources. That's always an issue. If we're doing I-294 we want to look at I-290, which is great for us. But now you're going to have to find IDOT to say okay, if we're going to fix this, can you get dollars to fix this? That's one of the issues for us. We're here. How do we get others to adjust their budgets? Cook county and DuPage county have been great to deal with on the Elgin-O'Hare and on I-90. They've been moving things around because we engaged with them early and because it's an opportunity. The other way we've figured this out with the locals as far as financing is to come up with a repayment structure." 
$\underline{\text { Technology and information sharing are the future of integration. }}$

Although the technology integration may not be ready, it is important for agencies to be forward-looking when implementing new technology so that it can be easier to implement data-sharing and/or intelligent transportation systems (ITS).

"Where I think the opportunity to kick it up a notch with freight and Pace is in real time information and about sharing that information with our users. If we are able to help some of our truck drivers to divert an incident up ahead by giving them alternative routes, I think that's the idea here. Likewise with Pace, if we have customers that are driving and they find that it's quicker for them to take Pace to the Blue Line to downtown. The technology is going to be installed in such a way that it can happen in the future."

\section{Highlights from the Interview with Pace}

Promote mobility management by engaging stakeholders early.

As a service provider, the interviewee from Pace placed a large emphasis on mobility management in terms of working with communities and potential riders to help accommodate the needs of travelers. He gave many examples integration with those players by working with developers to adjust routes to serve new office parks if the developers add features such as bus turnarounds, or adjusting service hours to better accommodate people as they get off. He stated that Pace works with townships and municipalities as well, to provide a "family of services". Pace also engages with communities to ensure the agency can be involved in these decisions as early as possible. He named DuPage County as an entity that is particularly good at bringing in stakeholders and soliciting feedback from a wide group.

$\underline{\text { Reward forward-looking visions and educate elected officials. }}$

An interesting stumbling block toward achieving integration that was mentioned in this interview is that although many players in the region have started developing long-term visions toward better mobility management and better connectivity in the region, the short-term processes continue to reward the old systems. This makes it more difficult for stakeholders in the region to change their way of operating toward greater integration. Other challenges to integration mentioned included funding and politics. Although there are many people at stakeholder agencies around the region who are champions of integration, there is a lack of elected officials in the region who are big champions of integration. 
$\underline{\text { A vision for integration need not be a static one. }}$

Many of the ideas presented in this interview were about changing mindsets of how transit can operate. As an example, he stated that Pace had previously thought of their bus rapid transit (BRT) routes in terms of individual bus lines but last year changed that thinking into considering them as one BRT network. Because the Pace system touches every major Interstate and many arterials, he expressed the view that part of Pace's goal is to relieve pressure from the road system. Working with those right of way (ROW) owners is a large part of integration in the eyes of Pace.

\section{Highlights from the Interview with Cook County}

Engage all of the stakeholders early to address jurisdictional challenges.

Transportation integration entails considering local jurisdiction in the context of multijurisdiction challenges. "Tollway is doing a great job on the Jane Addams, but everyone locally has to work with them, and if you want to put buses on the shoulder, they're going to have to get them off. You need to mix together Tollway's responsibility and somebody else's."

"You're not going to do a transportation network if all you're focused on is your jurisdiction or your mode of transportation. We have to think outside of our jurisdictions so we can create a multimodal corridor."

IDOT needs to provide leadership toward integration of transportation systems in the region.

"There needs to be a coming together. We need to realize that locals need help. We don't have all the plans for the roadway network. We have a great agency in CMAP, but they plan based on information that other people put in. They're an encyclopedia of information, but when it comes to implementing, how you connect these dots, they're not supposed to make those decisions. Somebody else needs to provide that. It's that kind of leadership that I think is lacking here. The planning people have to come in, the importance of economic development [has to be considered]. Those are all different departments in different places. First and foremost IDOT needs to acknowledge that and be willing to be at the table as one of the leaders."

Long range transportation plan is focused on policies, not on projects and communication among government officials is lacking. 
The Counties work together formally through meetings at CMAP. Work gets done informally through relationship-building. Local government often has relationships with business owners and other private interests. Consultants and contractors prevent government officials from talking to other government officials. This is because officials worry about accidentally speaking to consultants about upcoming projects. An informal event for personnel across agencies to socialize would help to build the relationships necessary for better integration.

The biggest challenge to interacting with other agencies is an "it's not my problem" attitude. Money is often given as an excuse, but the lack of will is the bigger culprit from his perspective.

There needs to be champions for integration.

"Tollway is speaking the right language regarding integration, but they are limited to working only in their ROWs and they often work too fast for locals. RTA and CMAP are also good champions of integration."

Data sharing is critical for transportation integration.

The County does not collect a lot of data. It could be worth considering consolidating data across jurisdictions so it is easier for the public to access. The examples given were truck permits and bridge information. This function could be undertaken by CMAP.

\section{Highlights from the Interview with DuPage County}

The DuPage County staff that participated in the integration interview are mid-level officials within the organization. As such, their perspective was more limited to the projects in which they are involved, unlike the high-level officials we interviewed from other agencies. The interview focused heavily on the Ride DuPage program, which is a paratransit service, and on an upcoming project to address first- and last-mile problems in the transit system of the County.

The DuPage County staff viewed mobility management as a goal, with the specific perspective of serving the paratransit users, as they are the main demographic utilizing their services. To that end, they viewed transportation integration as a means of achieving that goal and thought of integration primarily in terms of agencies coordinating services.

The DuPage County staff focused greatly on the needs of seniors and people with disabilities, but discussed that changing demographics in the county mean more of an 
emphasis on low-income working populations. They discussed the need for change in the system to better accommodate changing demographics and changing origin and destination demand. They discussed that a major barrier they face is trying to achieve greater public engagement, expressing that the majority of the residents of DuPage County do not use transit services and therefore do not see themselves as stakeholders.

\section{Summary}

The interviews with transportation professionals in this chapter offered a variety of opinions, insights and recommendations that are summarized in the table below.

\begin{tabular}{|l|l|l|l|l|}
\hline \multicolumn{4}{|c|}{ Key Themes from the Interviews of Participating Agencies } \\
\hline \multicolumn{1}{|c|}{ RTA } & \multicolumn{1}{|c|}{ ISTHA } & \multicolumn{1}{|c|}{ Pace } & Cook County & DuPage County \\
\hline $\begin{array}{l}\text { Transportation } \\
\text { integration can } \\
\text { be viewed in } \\
\text { both the } \\
\text { physical realm } \\
\text { and in terms of } \\
\text { policy } \\
\text { integration. }\end{array}$ & $\begin{array}{l}\text { Clear } \\
\text { understanding } \\
\text { vision is } \\
\text { integral to } \\
\text { integration. }\end{array}$ & $\begin{array}{l}\text { Promote } \\
\text { mobility } \\
\text { management } \\
\text { by engaging } \\
\text { stakeholders } \\
\text { early. }\end{array}$ & $\begin{array}{l}\text { Engage all of } \\
\text { the } \\
\text { stakeholders } \\
\text { early to } \\
\text { address } \\
\text { jurisdictional } \\
\text { challenges. }\end{array}$ & $\begin{array}{l}\text { Transportation } \\
\text { integration is a } \\
\text { means of } \\
\text { achieving } \\
\text { mobility } \\
\text { management. }\end{array}$ \\
\hline $\begin{array}{l}\text { Both formal } \\
\text { and informal } \\
\text { channels are } \\
\text { utilized to help } \\
\text { agencies work } \\
\text { together in the } \\
\text { region. }\end{array}$ & $\begin{array}{l}\text { Project timing } \\
\text { and resource } \\
\text { allocation. }\end{array}$ & $\begin{array}{l}\text { Reward } \\
\text { forward- } \\
\text { looking } \\
\text { visions and } \\
\text { educate } \\
\text { elected } \\
\text { officials. }\end{array}$ & $\begin{array}{l}\text { IDOT needs to } \\
\text { provide } \\
\text { leadership } \\
\text { toward } \\
\text { integration of } \\
\text { transportation } \\
\text { systems in the } \\
\text { region. }\end{array}$ & $\begin{array}{l}\text { Integration can } \\
\text { be thought } \\
\text { primarily in } \\
\text { terms of } \\
\text { agencies } \\
\text { coordinating } \\
\text { services. }\end{array}$ \\
\hline
\end{tabular}




\begin{tabular}{|c|c|c|c|c|}
\hline \multicolumn{5}{|c|}{ Key Themes from the Interviews of Participating Agencies } \\
\hline RTA & ISTHA & Pace & Cook County & DuPage County \\
\hline \multirow[t]{3}{*}{$\begin{array}{l}\text { The future of } \\
\text { integration } \\
\text { efforts ought to } \\
\text { be focused on } \\
\text { information } \\
\text { sharing. }\end{array}$} & $\begin{array}{l}\text { Technology } \\
\text { and } \\
\text { information } \\
\text { sharing are the } \\
\text { future of } \\
\text { integration. }\end{array}$ & $\begin{array}{l}\text { A vision for } \\
\text { integration } \\
\text { need not be a } \\
\text { static one. }\end{array}$ & $\begin{array}{l}\text { Long range } \\
\text { transportation } \\
\text { plan is focused } \\
\text { on policies, not } \\
\text { on projects, } \\
\text { and } \\
\text { communication } \\
\text { among } \\
\text { government } \\
\text { officials is } \\
\text { lacking. }\end{array}$ & $\begin{array}{l}\text { It is necessary } \\
\text { to focus greatly } \\
\text { on the needs of } \\
\text { seniors, people } \\
\text { with disabilities } \\
\text { and low-income } \\
\text { working } \\
\text { populations. }\end{array}$ \\
\hline & & & $\begin{array}{l}\text { There needs to } \\
\text { be champions } \\
\text { for integration. }\end{array}$ & $\begin{array}{l}\text { Achieving } \\
\text { greater public } \\
\text { engagement is } \\
\text { a major step } \\
\text { toward } \\
\text { integration. }\end{array}$ \\
\hline & & & $\begin{array}{l}\text { Data sharing is } \\
\text { critical for } \\
\text { transportation } \\
\text { integration. }\end{array}$ & \\
\hline
\end{tabular}




\section{CHAPTER 4. CONCLUSIONS}

This report has taken a broad look at transportation integration by providing an understanding of the different dimensions of integration as defined in the literature, followed by a scan of various best practices of integration/mobility case studies to provide a basis for understanding the significant issues associated with achieving improved mobility through integration. The takeaways from the case studies allowed the project team to develop a set of questions that were then used to engage regional stakeholders in northeast Illinois to understand their perspectives to integration of modes.

While the results of these interviews seemingly provide a very regional outlook, a closer look also reveals that there are enough parallels in the responses that can benefit other stakeholders from around the country who struggle with similar issues when it comes to mobility improvement.

One of the most important issues brought to the fore in this study is that integration of transportation can be categorized into at least four types (1) functional, (2) planning, (3) social, and (4) policy integration. The case studies of integration/mobility seem to indicate a consistent thread of the state DOT or the local MPO spearheading the effort in developing a strategic plan to further integration efforts in their jurisdiction. In cases such as in San Diego, it resulted in organizational restructuring, while in the case of Dallas many different stakeholders came together for the purpose of addressing congestion issues at a specific corridor. In all the case studies included in this report, there was a champion that forced the issue either through policy, planning, or through identification of funding.

Stakeholders in Northeast Illinois have reflected similar thoughts during the interviews. A clear understanding of the goals and vision, utilization of formal and informal channels to work together, making use of advances in technology to share information and data, identifying and agreeing on resource sharing, ensuring every stakeholder is included, seeking direction and leadership from the MPO or from the DOT (a champion), and seeking impactful public engagement from the very beginning have all been highlighted in the interviews. These factors are universally resonating when it comes to integration of modes and improving mobility in a region.

The following factors thus emerge as relevant to foster integration. Useful "integration" may be emerging or taking place across any or all of these dimensions that seem to central to any "integration" effort...

- Vision/mission - as you have begun to assess them; and the degree to which they are shared or agreed to among partnering agencies/organizations. 
- Performance and measurement systems - Degree to which partners are using customer-based measures of performance in addition to operational and financial measures.

- Collaboration - What is the scope, content and frequency of communications/collaboration among planning, provider and funding partners?

- Integration - To what extent do provider agencies share/integrate assets (facilities, vehicles, infrastructure, management systems, communications systems/info technology, etc), policy processes, priority-setting processes, personnel, financial resources, etc. with partners?

- Information Technology - What information systems and technologies are used to link planning, provider and funding partners to customer markets and to each other? How is management of these systems directed, operated?

- Organizational structure - How are planning, operations, policy-setting and financial roles organized? How has traditional organizational structure, roles, responsibilities and staff capacity changed in service of integration and MM goals? e.g do providers/partners have parallel, duplicative functions, organizational units, personnel? 


\section{REFERENCES}

1. Auerbach, L., M. Ruesch, and B. Hylen. Public Transport Integration. SPUTNIC Strategies for Public Transport in Cities, August 2009. http://documents.rec.org/publications/SPUTNIC2MO ptintegration AUG2009 ENG. pdf - accessed 2/4/16.

2. Baltes, M., B. Cronin, S. Mortensen, and D. Thompson. Managing Congestion with Integrated Corridor Management. Mass Transit. 2008, pp. 52-63.

3. Boarnet, M. and R. Crane. The influence of land use on travel behavior: specification and estimation strategies. Transportation Research Part A: Policy and Practice. Vol. 35, 2001, pp. 823-845.

4. Bus-On-Shoulders Peer Review. Regional Transportation Authority and AECOM, (August 2009).

5. Burkhardt, J. and J. McLary. The Business Case for Mobility Management. APTA. http://www.apta.com/resources/hottopics/mobility/Documents/Business-Case-forMobility-Management.pdf - accessed 2/4/16.

6. Chicago Area Transportation Study: Volume III. Chicago Area Transportation Study. July 1962. http://www.cmap.illinois.gov/c/document_library/get_file?uuid=188b3645dc55-4759-bcbc-93cb7f3c92a9\&groupld=20583.

7. City of Big Shoulders: Implementing a Bus-on-Shoulder Program in Chicago, IL. Transportation Research Forum Chicago, (October 11, 2012).

8. DART, et. al. Concept of Operations for the US-75 Integrated Corridor in Dallas, Texas. U.S. Department of Transportation. FHWA-JPO-08-004, 2008, pp. 1-148.

9. Dickens, Ian S. J. Park and ride facilities on light rail transit systems. Transportation. Vol. 18, No. 1, 1991, pp 23-36.

10. Farzin, J., W. Lenski, and J. Czarnecky. I-55 Bus on Shoulder Demonstration: In the Spirit of Time. Transport Chicago 2011 Conference, (June 3, 2011).

11. Federal Transit Administration: Progress and Challenges in Implementing and Evaluating the Job Access and Reverse Commute Program. Publication GAO-09496. GAO. United States Government Accountability Office, 2009.

12. Guo, Z. and N.H.M Wilson. Assessing the cost of transfer inconvenience in public transport systems: A case study of the London Underground. Transportation Research Part A: Policy and Practice. Vol. 45, No. 1, 2011 pp. 91-104.

13. I-55 Bus on Shoulder Demonstration: MPO Policy Committee presentation. Regional Transportation Authority, Pace, and IDOT, (January 10, 2011).

14. Idris, M. Y. I., et al. Car Park System: A Review of Smart Parking System and its Technology. Information Technology Journal. Vol. 8, No. 2, 2009, pp. 101-113.

15. IL HB1884 | 2011-2012 | 97th General Assembly. (2011, August 11). LegiScan. Retrieved July 10, 2013, from http://legiscan.com/IL/bill/HB1884/2011. 
16. IL HB3597 | 2011-2012 | 97th General Assembly. (2011, July 07). LegiScan. Retrieved June 24, 2013, from http://legiscan.com/lL/bill/HB3597/2011.

17. IL HJR0024 | 2011-2012 | 97th General Assembly. (2011, May 19). LegiScan. Retrieved June 27, 2013, from http://legiscan.com/lL/bill/HB3597/2011.

18. Intermodal Surface Transportation Efficiency Act of 1991. Federal Highway Administration. 1991.

19. Intermodal Transportation: DOT Could Take Further Actions to Address Intermodal Barriers. Publication GAO-07-718. GAO, United States Government Accountability Office, 2007.

20. Interstate 55 Technical Memorandum 2: Evaluation and Identification of Reasonable Alternatives. Regional Transportation Authority and RTA, (December 2009).

21. Litman, T. Quantifying the Benefits of Nonmotorized Transportation For Achieving Mobility Management Objectives. Victoria Transport Policy Institute. 2010.

22. Meligrana, J.F. Toward regional transportation governance: A case study of Greater Vancouver. Transportation. Vol. 26, No. 4, 1999, pp. 359-398.

23. Metaxatos, P. and P. Thakuriah (2009). Planning for Bus on Shoulders Operations in Northeastern Illinois: A Survey of Stakeholders. Transportation Research Record 2111, Transportation Research Board, National Research Council, Washington, D.C., $10-17$.

24. Michigan Department of Transportation. New Policy Initiatives and Transportation Intermodal Integration. 2012, pp. 1-13.

25. Miller, M.A., L. Englisher, B. Kaplan and R. Halvorsen. Transit Service Integration Practices: A Survey of U.S. Experiences. Transportation Research Record: Journal of the Transportation Research Board. Vol. 1927, 2005, pp. 101-111.

26. Musso, A. and M.V. Corazza. Improving Urban Mobility Management: Case Study of Rome. Transportation Research Record: Journal of the Transportation Research Board. Vol. 1956, 2006, pp. 52-59.

27. National Commission on Intermodal Transportation. Toward a National Intermodal Transportation System Final Report. National Commission on Intermodal Transportation, 1994.

28. Needs Assessment Report. Parking Management Guidance System. RTA and Wilbur Smith Associates. 1999.

29. New Horizons for Chicago Metropolitan Area. Chicago Transit Authority. Oct 1958. http://ia600202.us.archive.org/12/items/newhorizonsforch00chic/newhorizonsforch00 chic.pdf - accessed 2/4/16

30. Noel, Errol C. Park-and-Ride: Alive, Well, and Expanding in the United States. Journal of Urban Planning and Development. Vol. 114, No. 1, 1988, pp. 2-13.

31. Pace to expand I-55 Bus on Shoulders service on May 6. Pace Press Release, (April 30, 2013). Retrieved July 16, 2013, from http://www.pacebus.com/sub/news_events/ press_release_detail.asp?ReleaselD=604. 
32. Potter, S. and M.J. Skinner. On transport integration: a contribution to better understanding. Futures. Vol. 32, 2000, pp. 275-287.

33. Preston, J. What's so funny about peace, love and transport integration? Research in Transportation Economics. Vol. 29, 2010, pp. 329-338.

34. Project Report Categorical Exclusion Group 1: I-55 Bus-on-Shoulder Demonstration. Regional Transportation Authority and IDOT, (January 18, 2011).

35. Report on the potential for integrating rail service provided by the National Railroad Passenger Corporation with other modes. Federal Railroad Administration: Rail Passenger Programs, Washington D.C., 1976.

36. Report to the President Human Service Transportation Coordination: Executive Order 13330. United We Ride: Coordinating Council on Access and Mobility, 2005.

37. Resnick, Barry S. Regional Transportation Authority and Metra Parking Management Guidance System Demonstration Project. Urban Public Transportation Systems Proceedings of the Second International Conference. 2002, pp. 62-74.

38. Rivasplata, C., H. Iseki, and A. Smith. Transit Coordination in the U.S.: A Survey of Current Practice. Journal of Public Transportation. Vol. 15, No. 1, 2012, pp. 53-73.

39. Rodier, Caroline J. and Susan A. Shaheen. Transit-based smart parking: An evaluation of the San Francisco Bay area field test. Transportation Research Part C: Emerging Technologies. Vol. 18, No. 2, 2010, pp. 225-233.

40. Rodier, Caroline J., Susan A. Shaheen, and Tagan Blake. Smart Parking Pilot on the Coaster Commuter Rail Line in San Diego, California. California PATH Program, Institute of Transportation Studies, University of California at Berkeley, 2010.

41. Rogoff, P. MAP-21 Public Webcast: A Legislative Overview. Presented August 24,2012, http://fta.dot.gov/documents/MAP-21_Public_Presentation.pdf. Accessed November 26, 2012.

42. RTA Act 1983: http://www.rtachicago.com/about-the-rta/rta-act.html

43. RTAMS website : http://www.rtams.org/rtams/planningProgram.jsp?id=4

44. RTCP Proposed Approach General Assembly Report: http://www.rtams.org/reportLibrary/65.pdf

45. Sørensen, C.H. and F. Longva. Increased coordination in public transport - which mechanisms are available?. Transport Policy. Vol. 18, 2011, pp. 117-125.

46. Southworth, M. Designing the Walkable City. Journal of Urban Planning and Development. Vol. 131, No. 4, 2005, pp. 246-257.

47. Standard Tech Report. Parking Management Guidance System. RTA and Wilbur Smith Associates. 1999.

48. Stanley, J. and D.A. Hensher. Delivering trusting partnerships for route bus services: A Melbourne case study. Transportation Research Part A: Policy and Practice. Vol. 42, No. 10,2008 , pp. $1295-1301$.

49. Stanley, R.G. Supporting the Effort to Manage Mobility. American Public Transportation Association. 


\section{http://www.apta.com/resources/hottopics/mobility/Pages/SupportingtheEffort.aspx -} accessed 2/4/16.

50. Taylor, B.D. and L. Schweitzer. Assessing the experience of mandated collaborative inter-jurisdictional transport planning in the United States. Transport Policy. Vol. 12, No. 6, 2005, pp. 500-511.

51. Thakuriah, P., P. Metaxatos, and K. Mohammadian (2010). Bus Riding on Shoulders. Research Report FHWA-ICT-10-073. Illinois Center for Transportation, August 2010.

52. Thakuriah, P., S. Sööt, and P.S. Sriraj. Partnerships for the Job Access and Reverse Commute Program: A Multi-Site Study of the Institutional and Coordination Processes Behind Employment Transportation for Low-Income Workers. Urban Transportation Center at the University of Illinois at Chicago. 2008, pp. 1-18.

53. Transit Bus on Expressway Shoulder: I-55 Demonstartion Project. Regional Transportation Authority, Pace, and IDOT, (January 14, 2011).

54. Transit Priority Initiatives: Report to Illinois General Assembly. Regional Transportation Authority, (July 2011).

55. United We Ride. Mobility Management. 2007. pp. 1-4.

56. Vogel, R.K. and N. Nezelkewicz. Metropolitan Planning Organizations and the New Regionalism: The Case of Louisville. Publius. Vol. 32, No. 1, pp. 107-129.

57. Vuchic, V. Transportation for Livable Cities. Center for Urban Policy Research: Rutgers, The state University of New Jersey, New Brunswick, 1999.

58. Wilhelm, A. and K.H. Posch. Transportation Research Record: Journal of the Transportation Research Board. Vol. 1839, 2003, pp. 173-181.

59. Advances in Strategies for Implementing Integrated Corridor Management (ICM). NCHRP Project 20-68A. National Cooperative Highway Research Program. http://www.domesticscan.org/wp-content/uploads/NCHRP20-68A 12-02.pdf accessed 2/4/16. 